\title{
Microstructure evolution of a novel low-density Ti-Cr-Nb-V refractory high entropy alloy during cold rolling and subsequent annealing
}

\author{
N. Yu Yurchenko ${ }^{a}$, E.S. Panina ${ }^{a}$, S.V. Zherebtsov ${ }^{a}$, M.A. Tikhonovsky ${ }^{b}$, G.A. Salishchev ${ }^{a}$, \\ N.D. Stepanov ${ }^{\mathrm{a}, *}$ \\ ${ }^{a}$ Laboratory of Bulk Nanostructured Materials, Belgorod State University, Belgorod, 308015, Russia \\ b National Science Center "Kharkov Institute of Physics and Technology" NAS of Ukraine, Kharkov, 61108, Ukraine
}

\section{A R T I C L E I N F O}

\section{Keywords:}

High entropy alloys

Phase diagrams

Thermomechanical processing

Strengthening

Electron microscopy

Mechanical properties

\begin{abstract}
A B S T R A C T
Refractory high entropy alloys represent a new class of metallic alloys attractive for high-temperature applications. However, most of the developed alloys have either low ductility at room temperature or high density. In this work, we report structure and mechanical properties of a novel non-equiatomic $\mathrm{Ti}_{1.89} \mathrm{CrNbV}_{0.56}$ alloy produced by vacuum arc melting. The density of the alloy was $6.17 \mathrm{~g} / \mathrm{cm}^{3}$. In the as-cast condition, the alloy had a single-phase bcc structure enabling room temperature deformation in compression to $\varepsilon>50 \%$ or cold-rolling to a thickness strain of $80 \%$. Rolling resulted in the formation of a dislocation substructure and development of kink and shear bands. Meanwhile, microhardness measurements have revealed only a moderate increase from $396 \mathrm{HV}$ in the as-cast condition to $454-469 \mathrm{HV}$ after $40-80 \%$ rolling. After $80 \%$ cold rolling the alloy had yield strength of $1020 \mathrm{MPa}$, ultimate tensile strength of $1535 \mathrm{MPa}$, and elongation to fracture of $3.5 \%$. The cold rolled alloy was annealed at 800,1000 or $1200^{\circ} \mathrm{C}$ for $1-100 \mathrm{~h}$. Microstructural response to the annealing strongly depended on temperature. Annealing at $800^{\circ} \mathrm{C}$ mostly resulted in Cr-rich fcc (C15) Laves phase particles precipitation. Annealing at $1000^{\circ} \mathrm{C}$ led to the bcc matrix recrystallization along with the precipitation of the Laves phase particles, thereby producing a fine duplex microstructure. Finally, annealing at $1200{ }^{\circ} \mathrm{C}$ resulted in a coarse-grained recrystallized single-phase bcc microstructure. Microhardness of the alloy lowered with an increase in the annealing temperature while the annealing time had a small effect on hardness.
\end{abstract}

\section{Introduction}

Materials able to withstand high temperatures are always in high demand, especially in the aerospace sector [1]. Recently, a new class of promising high-temperature metallic alloys has emerged. These alloys are composed of multiple refractory elements taken in high concentrations with the possible presence of other non-refractory elements and are termed refractory high entropy alloys (RHEAs) or refractory complex, concentrated alloys (RCCAs) [2-4]. These alloys tend to have structures based on a body-centered cubic (bcc) solid solution with the presence of some other phases (e.g. B2 or Laves) [3]. RHEAs/RCCAs often demonstrate high strength at elevated temperatures, making them promising for high-temperature applications $[3,4]$. Note that the firstdeveloped RHEAs/RCCAs had, along with impressive strength at temperatures up to $1600{ }^{\circ} \mathrm{C}$, a very high density of $10-12 \mathrm{~g} / \mathrm{cm}^{3}[5,6]$. Further studies have resulted in the development of alloys with a much lower density (down to $\sim 5.5 \mathrm{~g} / \mathrm{cm}^{3}[7,8]$ ) that were superior to currently-used Ni-based superalloys in specific strength at temperatures up to $1200{ }^{\circ} \mathrm{C}$ [9-16].

However, additional research efforts are required to develop RHEAs/RCCAs with a balanced combination of relevant properties. For instance, most of the alloys with high strength at elevated temperatures have low ductility, as it was reported for a series of low-density $\left(\sim 6.5 \mathrm{~g} / \mathrm{cm}^{3}\right) \mathrm{Cr}-\mathrm{Ti}-\mathrm{Nb}-\mathrm{V}-\mathrm{Zr}$ alloys $[17,18]$. Cr-containing alloys were found to be superior to Ni-based superalloys in high specific strength at temperatures up to $1000{ }^{\circ} \mathrm{C}$; but due to the presence of a large amount of the Laves phase ductility of the alloys was quite limited. At the same time although alloys without $\mathrm{Cr}$ had high enough ductility in compression, their strength was too low for any potential high-temperature application.

It should be mentioned that ductility is important from both service and technological viewpoints. Generally, materials with high ductility have good damage tolerance which is a crucial property for the demanding applications. Also, ductile enough materials can be readily thermomechanically processed to improve structure and properties. However the only known example of using thermomechanical

\footnotetext{
* Corresponding author. Laboratory of Bulk Nanostructured Materials, Belgorod State University, Pobeda 85, Belgorod, 803015, Russia.

E-mail addresses: stepanov@bsu.edu.ru, stepanov.nikita@icloud.com (N.D. Stepanov).
} 
treatment of RHEAs/RCCAs is the equiatomic HfNbTaTiZr alloy cold rolled to a large thickness strain [19-25]. However, the HfNbTaTiZr alloy has a relatively high density and softens quickly at elevated temperatures [26,27].

It has already been well established that variations in concentrations of the constitutive elements, i.e. deviation from their non-equiatomic proportions, can be beneficial for production of HEAs with promising properties, superior to equiatomic counterparts. This approach has been used extensively for HEAs based on late $3 \mathrm{~d}$ transition metals [28-35], but not often applied to RHEAs/RCCAs [36]. In this work, microstructure and microhardness evolution during cold rolling and subsequent annealing at $800-1200{ }^{\circ} \mathrm{C}$ of a new non-equiatomic $\mathrm{Ti}-\mathrm{Cr}-\mathrm{Nb}-\mathrm{V}\left(\mathrm{Ti}_{1.89} \mathrm{CrNbV}_{0.56}\right)$ RHEA, developed on the basis of earlier results on the Al-Cr-Nb-Ti-V-Zr system RHEAs/RCCAs [7,8,13,37-43], are studied in details.

\section{Materials and methods}

The $\mathrm{Ti}_{1.89} \mathrm{CrNbV}_{0.56}$ alloy ingot measured $\sim 10 \times 14 \times 50 \mathrm{~mm}^{3}$ was produced by arc melting of the elements in low-pressure, high-purity argon atmosphere inside a water-cooled copper cavity. The purities of the alloying elements were no less than $99.9 \mathrm{wt} . \%$. The nominal and actual chemical compositions of the alloy (the latter was measured by energy dispersive spectrometry (EDS); the scan area was $\sim 1 \times 1 \mathrm{~mm}^{2}$ ) are presented in Table 1 . The measured composition closely corresponded to the nominal one. The density of the alloy was determined using hydrostatic weighting (Archimedes' principle) of three samples measured $4 \times 4 \times 6 \mathrm{~mm}^{3}$.

Rectangular samples measured $8 \times 10 \times 20 \mathrm{~mm}^{3}$ for thermomechanical processing were cut from the as-cast ingot by electric discharge machine. Unidirectional multipass rolling using a fixed rolling speed of $30 \mathrm{~mm} / \mathrm{s}$ at room temperature to a total thickness strain $\varepsilon_{\text {th }}=80 \%$ was performed in air using a reduction per pass of approximately $0.07-0.15 \mathrm{~mm}$. Some rolled specimens were annealed at 800 and $1000^{\circ} \mathrm{C}$ for 1,10 , or $100 \mathrm{~h}$ with further air cooling. Prior to the annealing, samples were sealed in vacuumed $\left(10^{-2}\right.$ torr) quartz tubes filled with titanium chips to prevent oxidation. Similar procedures were used to anneal the alloy at $1200^{\circ} \mathrm{C}$ for 1,10 , and $25 \mathrm{~h}$.

Structure of the alloy in the as-cast condition, after rolling and annealing was studied using X-ray diffraction (XRD), transmission (TEM) and scanning (SEM) electron microscopy; the latter was equipped by energy dispersive X-ray (EDX) spectrometry and electron backscattered diffraction (EBSD) units. XRD analysis was performed using a Rigaku diffractometer with CuKa radiation. Microstructural investigations of the rolled samples were carried out in a plane perpendicular to the transversal direction. Specimens for SEM observations and EBSD analysis were prepared by careful mechanical polishing. SEM back-scattered electron (BSE) images were taken using a FEI Quanta 600 FEG microscope equipped also with an EDS detector. EBSD analysis was conducted in a FEI Nova NanoSEM 450 microscope equipped with a Hikari EBSD detector and a TSL OIM ${ }^{\mathrm{TM}}$ system version 6.0. Points with the confidence index (CI) $\leq 0.1$ were excluded from analysis. Dislocation density was calculated using Kernel average misorientation (KAM) maps according to equation (1) [44]:

Table 1

The chemical composition of the structural constituents of the program alloy in the as-cast condition and the nominal composition of the alloy (in. at.\%).

\begin{tabular}{|c|c|c|c|c|}
\hline Element & $\mathrm{Ti}$ & $\mathrm{Cr}$ & $\mathrm{Nb}$ & $\mathrm{V}$ \\
\hline \multicolumn{5}{|l|}{ Constituent } \\
\hline Denrite & 40.8 & 23.6 & 23.8 & 11.8 \\
\hline Interdendrite & 45.1 & 20.7 & 21.7 & 12.5 \\
\hline Actual alloy composition & 42.7 & 22.1 & 23.0 & 12.2 \\
\hline Nominal alloy composition & 42.5 & 22.5 & 22.5 & 12.5 \\
\hline
\end{tabular}

$\rho=\frac{2 \sqrt{3}}{3} \times \frac{\theta}{b \times h}$,

where $\rho$ is the dislocation density, $\theta$ denotes KAM, $b$ is the Burgers vector and $h$ is the step size during EBSD scanning.

Specimens for TEM analysis were prepared by conventional twin-jet electro-polishing of mechanically pre-thinned to $100 \mu \mathrm{m}$ foils, in a mixture of methanol $(600 \mathrm{ml})$, butanol $(360 \mathrm{ml})$, and perchloric acid $(60 \mathrm{ml})$ at a temperature of $-35^{\circ} \mathrm{C}$ and an applied voltage of $29.5 \mathrm{~V}$. TEM investigations were performed using a JEOL JEM-2100 microscope with an accelerating voltage of $200 \mathrm{kV}$.

Vickers microhardness tests of specimens after both rolling to $\varepsilon_{\text {th }}=5-80 \%$ and annealing at $600-1100{ }^{\circ} \mathrm{C}$ were conducted at room temperature using $300 \mathrm{~g}$ load. At least 10 measurements per each data point were made. The nanohardness was determined via the Oliver and Pharr method [45] using a Shimadzu DUH-211s Dynamic Ultra Micro Hardness Tester equipped with a Berkovich indenter. At least twenty indents were performed with the maximum load of $50 \mathrm{mN}$ for $5 \mathrm{~s}$; a loading speed was $6.6620 \mathrm{mN} / \mathrm{s}$. Isothermal compressions of rectangular specimens measured $4 \times 4 \times 6 \mathrm{~mm}^{3}$ were carried out at room temperature using an Instron 300LX test machine. The initial strain rate was $10^{-4} \mathrm{~s}^{-1}$. For the tensile tests, specimens with the gauge dimensions of $1.5 \times 3 \times 6 \mathrm{~mm}^{3}$ were cut from the cold-rolled alloy by electric discharge machine and carefully mechanically polished. Specimens were pulled to fracture using Instron 5882 test machine at initial strain rate of $10^{-4} \mathrm{~s}^{-1}$. Strain was measured by a contact extensometer.

The equilibrium phase diagram was constructed using a ThermoCalc (version 2017b) software and a TCHEA2 (high-entropy alloys) database.

\section{Results}

\subsection{As -cast structure and properties}

In the as-cast condition the $\mathrm{Ti}_{1.89} \mathrm{CrNbV}_{0.56}$ alloy had a single-phase bcc microstructure (Fig. 1a) with coarse and relatively equiaxed grains (Fig. 1b). The lattice parameter of the bcc phase and the average size of bcc grains were $0.3163 \pm 0.0005 \mathrm{~nm}$ and $150 \pm 80 \mu \mathrm{m}$, respectively. SEM-BSE images (Fig. 1b) also demonstrated the presence of dendritic segregations. SEM-EDX analysis revealed that the lighter (dendrite) areas are slightly enriched with $\mathrm{Nb}$ and $\mathrm{Cr}$, whereas the darker (interdendrite) parts are enriched with Ti (Table 1). Vanadium was found to be distributed homogeneously. TEM images with the corresponding selected area electron diffraction (SAED) pattern (Fig. 1c) confirmed the single-phase disordered bcc structure.

Fig. 1d shows a stress-strain curve of the program alloy obtained during compression testing at room temperature. After attaining the yield point at $990 \mathrm{MPa}$, the alloy demonstrated a continuous strain hardening stage. Due to rather high compression ductility the alloy did not fracture after a height reduction of $50 \%$. The measured density of the alloy was $6.17 \mathrm{~g} / \mathrm{cm}^{3}$.

\subsection{Microstructure evolution during cold rolling}

Microstructure of the cold rolled alloy was primarily studied by EBSD (Fig. 2). At the initial stages of deformation the microstructural response was associated with the development of substructure in some grains with preferential crystallographic orientation (Fig. 2a). With an increase in strain, the substructure development became evident in the majority of grains (Fig. 2b). In addition, some lens-shaped areas surrounded by medium-angle boundaries of $\sim 15-20^{\circ}$ (see insert in Fig. $2 \mathrm{~b}$; the misorientation was determined along the black arrow in Fig. 2b) could be observed inside some grains. With further increase in rolling strain, the development of such lens-shaped areas became more pronounced; the misorientation of their boundaries increased to $30-60^{\circ}$ (see insert in Fig. 2c; the misorientation was determined along the red 
A

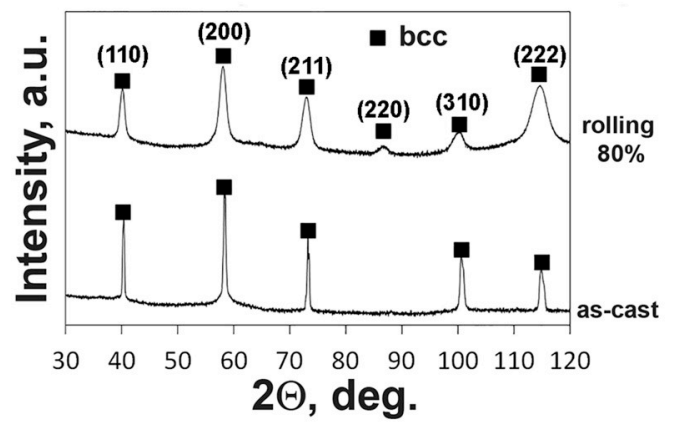

B

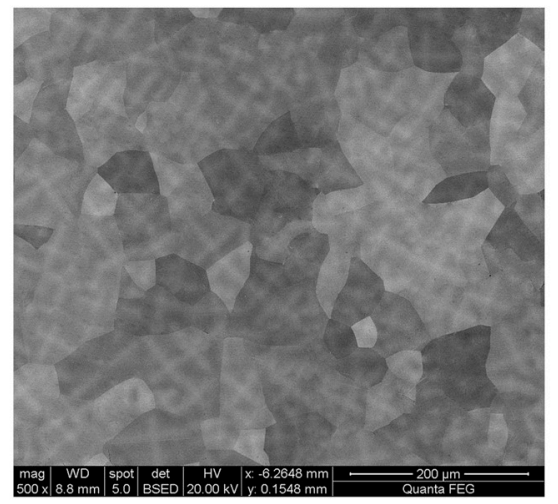

C

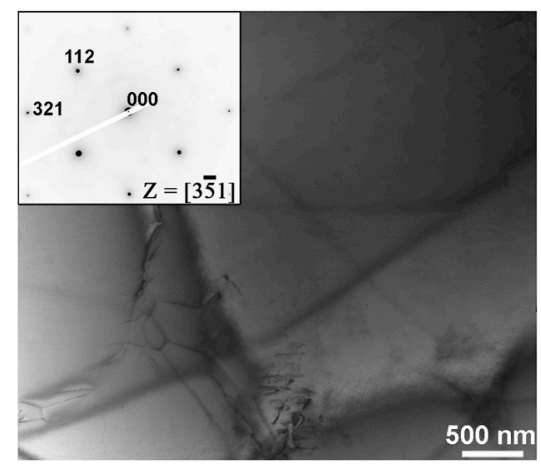

D

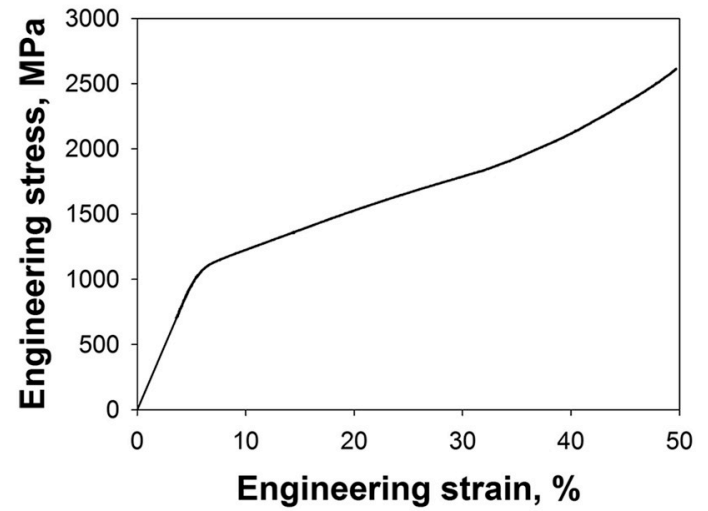

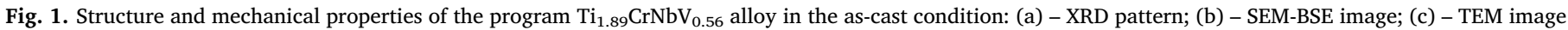
with the corresponding selected area electron diffraction pattern (SAED); (d) - stress-strain curve obtained in compression at room temperature.

arrow in Fig. 2c). Also, flattening of the initial grains was noted. At even higher rolling strains, shear bands started forming (Fig. 2d). As a result, a typical heavily-deformed microstructure composed of elongated remnants of the initial grains subdivided by the shear bands was observed after rolling to a thickness strain $\left(\varepsilon_{\mathrm{th}}\right)$ of $80 \%$ (Fig. 2e). Note that despite the high degree of rolling strain, some areas remained almost intact.

Fig. 3 presents the dependence of dislocation density, derived from EBSD data using Eq. (1), on thickness strain. The dependence showed a stable increase in the dislocation density with strain. For instance, in the initial (as-cast) condition the dislocation density was $0.8 \times 10^{13} \mathrm{~m}^{-2}$, while after $\varepsilon_{\text {th }}=80 \%$ the dislocation density was $8.4 \times 10^{13} \mathrm{~m}^{-2}$, i.e. an order of magnitude higher.

To gain further insight into the deformed microstructures of the alloy, TEM investigations were performed (Fig. 4). At low strains $\left(\varepsilon_{\text {th }}=20 \%\right)$ dislocation were mostly arranged in relatively thick linear arrays with numerous homogeneously distributed dislocations in between them (Fig. 4a). The selected area electron diffraction (SAED) pattern (insert in Fig. 4a) showed some azimuthal scattering of reflections thereby suggesting small misorientations between the areas separated by these linear arrays of dislocation. An increase in $\varepsilon_{\text {th }}$ to $80 \%$ resulted also in a highly inhomogeneous structure with a pronounced difference in dislocation density in different areas (compare the upper right and lower left corners in Fig. 4b, for example). In some cases elongated areas with a thickness of several hundred nanometers were bordered by thin sharp boundaries; these areas were inclined from the rolling direction. Rather scattered reflections on the SAED pattern (insert in Fig. 4b) suggested noticeable higher misorientations between different areas in comparison with that at the lower strains. Note that SAEDs have not revealed the presence of any other phase than the bcc one; this finding was consistent with the XRD data (Fig. 1c).

\subsection{Effect of annealing on structure}

Fig. 5 shows XRD patterns of the program $\mathrm{Ti}_{1.89} \mathrm{CrNbV}_{0.56}$ alloy annealed at $800^{\circ} \mathrm{C}$ (Figs. 5a), $1000{ }^{\circ} \mathrm{C}$ (Fig. 5b), or $1200^{\circ} \mathrm{C}$ (Fig. 5c) for 1,10 , or $100 \mathrm{~h}\left(25 \mathrm{~h}\right.$ only at $\left.1200^{\circ} \mathrm{C}\right)$ following cold rolling. Annealing at $800^{\circ} \mathrm{C}$ and $1000^{\circ} \mathrm{C}$ resulted in the appearance of a new phase in addition to the bcc solid solution found both in the as-cast or cold rolled alloy (Fig. 1a). This new phase was identified as a C15 face-centered cubic (fcc) Laves phase. After annealing at $800{ }^{\circ} \mathrm{C}$ the lattice parameters of the bcc and C15 phases were $0.3230 \pm 0.0002$ $-0.3231 \pm 0.0004 \mathrm{~nm}$ and $0.7004 \pm 0.0007-0.7010 \pm 0.0010 \mathrm{~nm}$, respectively. In turn, annealing at $1000^{\circ} \mathrm{C}$ resulted in the formation of both the bcc phase with the lattice parameter of 0.3198 $\pm 0.0003-0.3200 \pm 0.0004 \mathrm{~nm}$ and the Laves phase with the lattice parameter of $0.7008 \pm 0.0009-0.7012 \pm 0.0007 \mathrm{~nm}$. At either this temperature ( 800 or $1000{ }^{\circ} \mathrm{C}$ ), an increase in the annealing time from 1 to $100 \mathrm{~h}$ resulted in a gradual increase in the intensity of C15 Laves phase maximums. However, after annealing at $1200^{\circ} \mathrm{C}$ a single bcc phase was detected by XRD (Fig. 5c). The lattice parameter of the bcc phase was $0.3169 \pm 0.0001-0.3170 \pm 0.0002 \mathrm{~nm}$. Note splitting of peaks corresponding to the bcc phase at high angles.

Fig. 6 illustrates microstructure of the cold-worked $\mathrm{Ti}_{1.89} \mathrm{CrNbV}_{0.56}$ alloy after annealing at $800{ }^{\circ} \mathrm{C}$ for $1-100 \mathrm{~h}$. Apparently, the annealing resulted in a decomposition of the bcc solid solution and precipitation of numerous fine second phase particles. According to the XRD results (Fig. 5a), these particles can be identified as the Laves phase. In SEMBSE images the Laves phase particles are seen as brighter areas (Fig. 6). After annealing for $1 \mathrm{~h}$ (Fig. 6a), most of these particles had a rectangular shape with the average length and width of $0.75 \pm 0.27 \mu \mathrm{m}$ and $0.28 \pm 0.09 \mu \mathrm{m}$, respectively. The fraction of the particles was found to be 0.23 . Chemical analysis have revealed that the particles were 
A

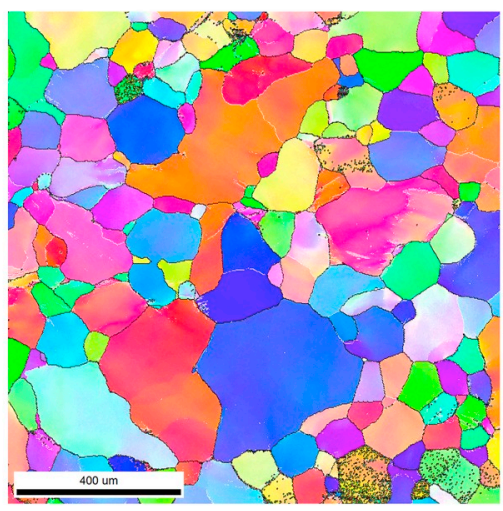

C

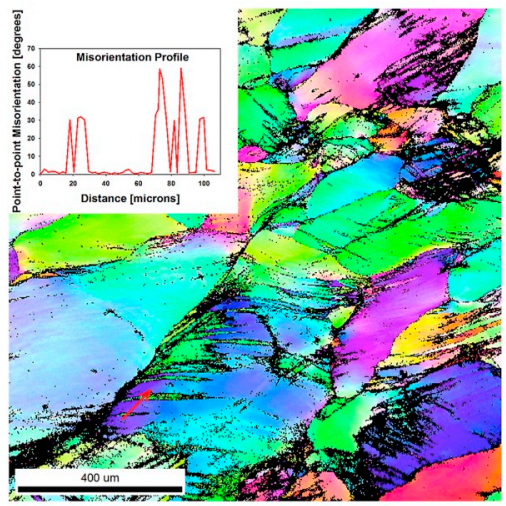

$\mathrm{B}$

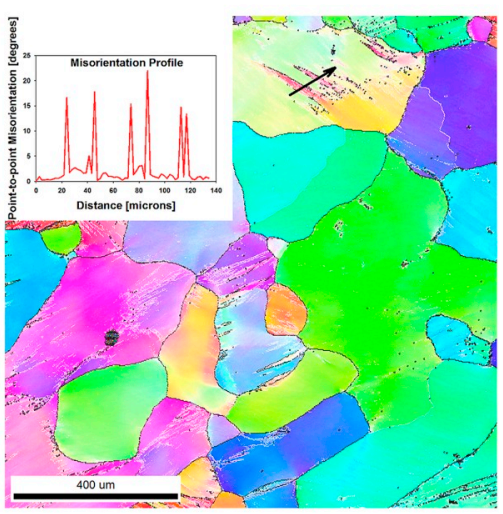

D

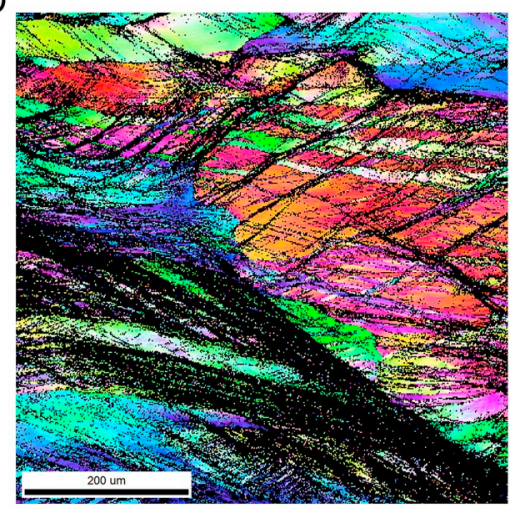

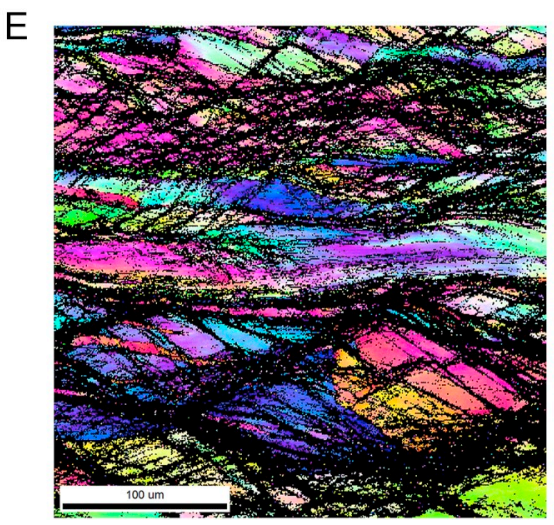

Fig. 2. EBSD IPF maps of the program $\mathrm{Ti}_{1.89} \mathrm{CrNbV}_{0.56}$ alloy after cold rolling to a thickness strain $\varepsilon_{\text {th }}$ of $10 \%$ (a); $\varepsilon_{\text {th }}=20 \%$ (b); $\varepsilon_{\text {th }}=40 \%$ (c); $\varepsilon_{\text {th }}=60 \%$ (d); or $\varepsilon_{\mathrm{th}}=80 \%$ (e). The rolling direction is horizontal in all cases. Black and red arrows in Fig. $2 \mathrm{~b}$ and c, respectively, indicate the lines used for misorientation profiling (inserts in Fig. 2b and c). (For interpretation of the references to colour in this figure legend, the reader is referred to the Web version of this article.)

enriched with $\mathrm{Cr}$ (26.7 at.\%) and depleted of Ti (38.7 at.\%) (Table 2). In turn, the matrix was depleted of $\mathrm{Cr}$ and enriched with $\mathrm{Ti}$. An increase in the annealing duration resulted in modest changes in the microstructure (Fig. 6b and c). In particular, the Laves phase particles shape became closer to the equiaxed one; the length and width of the particles after annealing for $10 \mathrm{~h}$ was found to be $0.59 \pm 0.27 \mu \mathrm{m}$ and $0.31 \pm 0.19 \mu \mathrm{m}$, respectively, and after annealing for $100 \mathrm{~h}$ $0.62 \pm 0.23 \mu \mathrm{m}$ and $0.38 \pm 0.19 \mu \mathrm{m}$, respectively. The fraction of the particles increased to 0.30 and 0.43 after annealing for 10 and $100 \mathrm{~h}$, respectively. In addition concentration of $\mathrm{Ti}$ in the particles decreased (to 36.1 at.\% after $100 \mathrm{~h}$ ), while the concentration of $\mathrm{Cr}$ increased (to 28.7 at.\%) (Table 2). The concentration of $\mathrm{Cr}$ in the matrix reduced to 17.7 at.\%.
To estimate the effect of annealing on the bcc matrix phase of $\mathrm{Ti}_{1.89} \mathrm{CrNbV}_{0.56}$, EBSD scanning after annealing at $800^{\circ} \mathrm{C}$ for $100 \mathrm{~h}$ was carried out (Fig. 6d). One can see that the microstructural response to the annealing was mostly associated with recovery of the bcc phase (i.e. formation of low-angle subgrain boundaries) rather than recrystallization.

Microstructure of the $\mathrm{Ti}_{1.89} \mathrm{CrNbV}_{0.56}$ alloy after annealing at $1000{ }^{\circ} \mathrm{C}$ is shown in Fig. 7. Similarly to annealing at $800^{\circ} \mathrm{C}$ (Fig. 6), a dual-phase microstructure composed of the bcc matrix and the Laves phase particles. However, the Laves phase particles were considerably coarser and had a polygonal shape with mainly straight boundaries. The Laves phase particles size increased from $0.82 \pm 0.40 \mu \mathrm{m}$ after annealing for $1 \mathrm{~h}$ (Fig. 7a) to $2.94 \pm 1.21 \mu \mathrm{m}$ after $100 \mathrm{~h}$ (Fig. 7c). The 


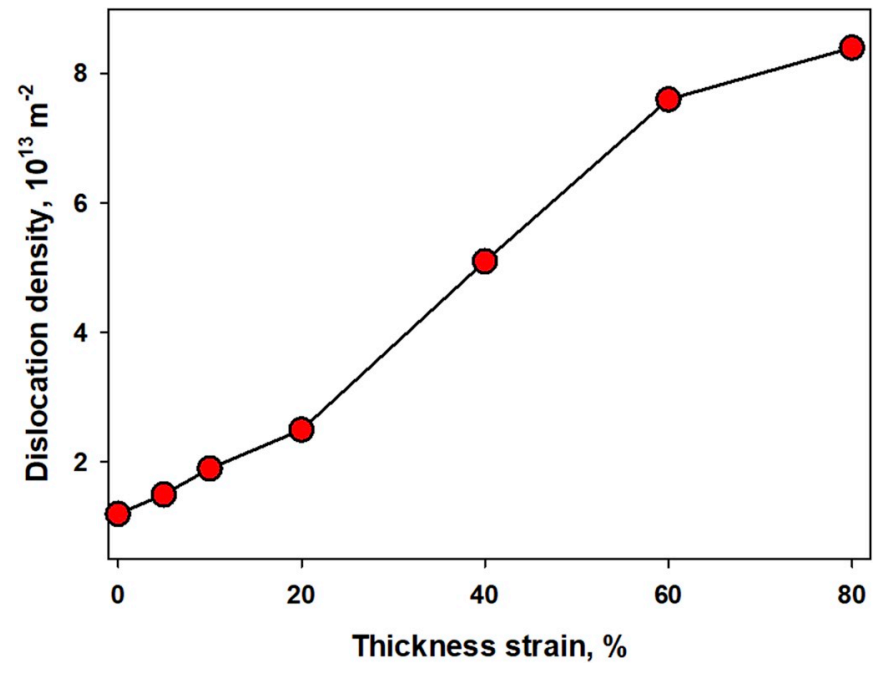

Fig. 3. Dependence of dislocation density in the program $\mathrm{Ti}_{1.89} \mathrm{CrNbV}_{0.56}$ alloy on thickness strain.

fraction of the particles also increased from 0.25 (after an hour annealing) to $0.36(100 \mathrm{~h})$. Numerous annealing twins were found in the Laves phase particles. The Laves phase particles were mostly composed of $\mathrm{Cr}$ ( 35-50 at.\%) and depleted of Ti (19-32 at.\%) (Table 3). In turn, the matrix was enriched with $\mathrm{Ti}(\sim 46-53$ at.\%). In the matrix formation of recrystallized polygonal bcc phase grains was observed; the Laves phase particles were often found on the grain boundaries and/or triple junctions of the new grains. The average size of the recrystallized grains increased from $1.9 \pm 1.1 \mu \mathrm{m}$ after annealing for $1 \mathrm{~h}$ to $5.6 \pm 2.8 \mu \mathrm{m}$ after $100 \mathrm{~h}$ annealing.

After annealing at a higher temperature of $1200^{\circ} \mathrm{C}$, the alloy had a single bcc phase coarse-grained structure (Fig. 8). The recrystallized bcc grains had mainly a polygonal shape with straight clean boundaries. The size of the recrystallized grains gradually increased from $145 \pm 80 \mu \mathrm{m}$ after annealing for 1 four (Fig. 8a) to $180 \pm 90 \mu \mathrm{m}$ (Fig. 8b) and to $210 \pm 110 \mu \mathrm{m}$ (Fig. 8c) after annealing for 10 or $25 \mathrm{~h}$, respectively. The chemical composition of the grains was nearly identical to the nominal composition of the alloy (Table 1 ). Note that the well-recrystallized structure of the alloy after annealing at $1200^{\circ} \mathrm{C}$ can most likely be the reason for the bcc peaks splitting (due to presence of $\mathrm{K}_{\alpha 1} / \mathrm{K}_{\alpha 2}$ doublets [46]) at high angles of the XRD patterns (Fig. $5 \mathrm{c}$ ).

\subsection{Microhardness evolution}

To evaluate the effect of cold rolling with subsequent annealing on mechanical properties of the $\mathrm{Ti}_{1.89} \mathrm{CrNbV}_{0.56}$ alloy microhardness
A

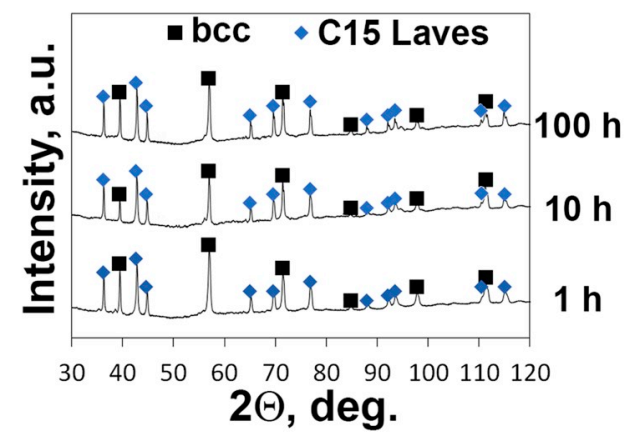

B

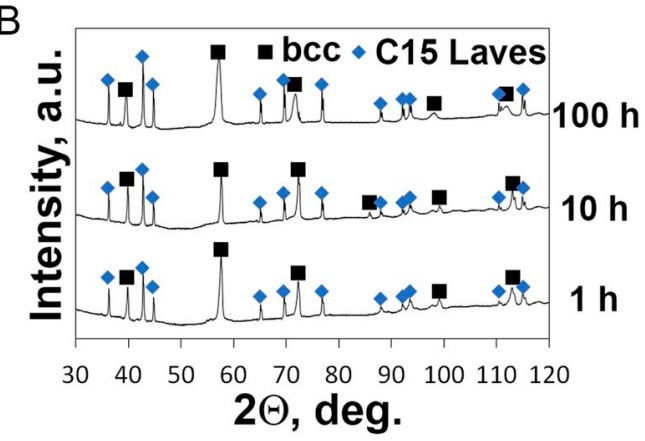

C

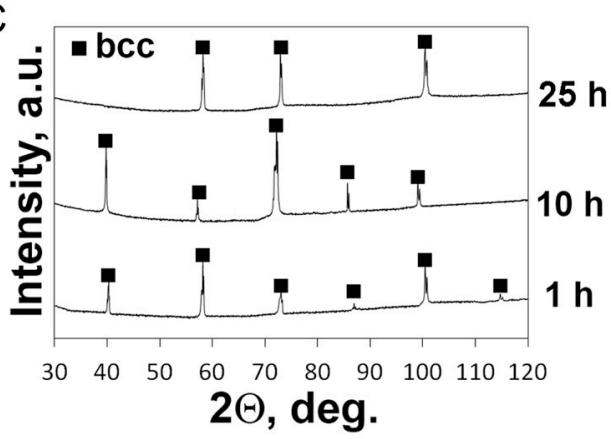

Fig. 5. XRD patterns of the program $\mathrm{Ti}_{1.89} \mathrm{CrNbV}_{0.56}$ alloy after cold rolling to $\varepsilon_{\text {th }}=80 \%$ and further annealing for $1-100 \mathrm{~h}$ at $800^{\circ} \mathrm{C}(\mathrm{a}), 1000^{\circ} \mathrm{C}(\mathrm{b})$, or $1200^{\circ} \mathrm{C}(\mathrm{c})$.

measurements were performed. The alloy in the as-cast condition had the microhardness of $396 \mathrm{HV}$. At the initial stages of rolling, the hardness increased quickly to $459 \mathrm{HV}$ after $20 \%$ thickness strain (Fig. 9). Further increase in strain did not result in noticeable changes

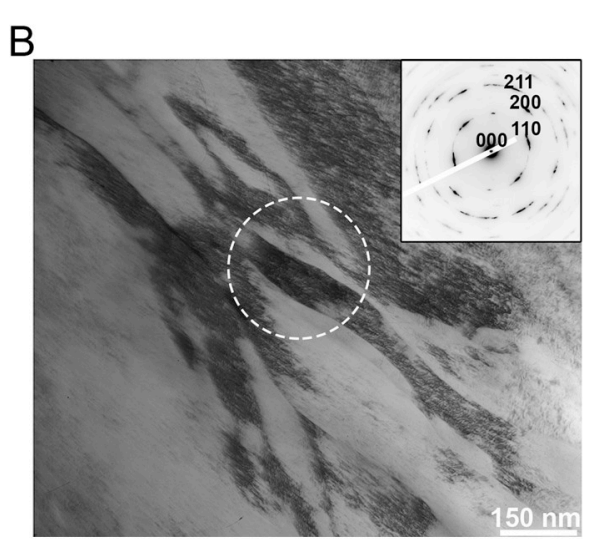

Fig. 4. TEM bright-field images (with corresponding SAED patterns) from a transversal plane of the program $\mathrm{Ti}_{1.89} \mathrm{CrNbV}_{0.56}$ alloy after rolling to $\varepsilon_{\text {th }}=20 \%$ (a) and $\varepsilon_{\mathrm{th}}=80 \%$ (b). Circles indicate areas used for obtaining the SAED patterns. The rolling direction is horizontal in both cases. 
A

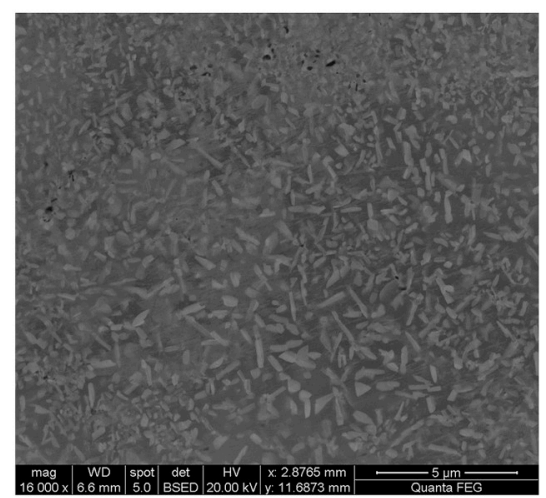

C

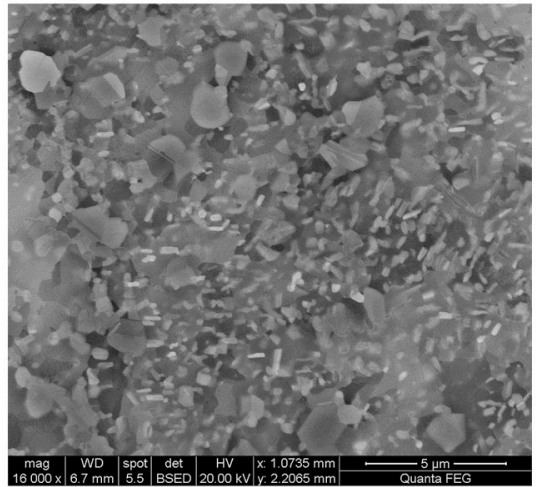

B

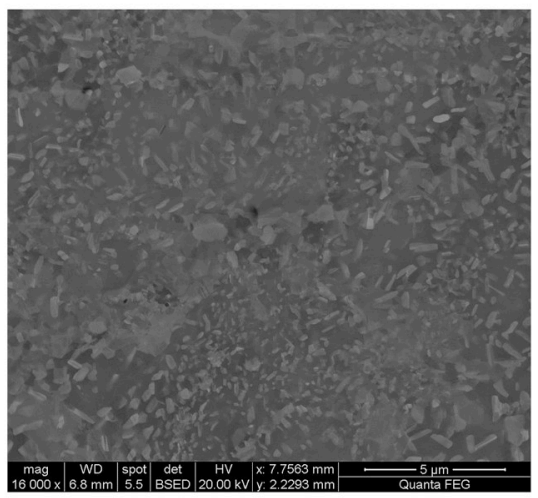

$\mathrm{D}$

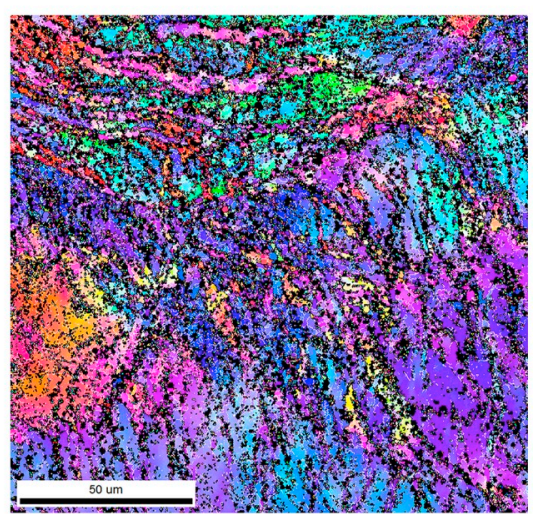

Fig. 6. Microstructure of the $\mathrm{Ti}_{1.89} \mathrm{CrNbV}_{0.56}$ alloy after cold rolling to $\varepsilon_{\text {th }}=80 \%$ and further annealing at $800{ }^{\circ} \mathrm{C}$ for $1 \mathrm{~h}$ (a); $10 \mathrm{~h}$ (b); or $100 \mathrm{~h}$ (c, d); SEM-BSE images (a-c) and EBSD IPF map for the bcc phase.

Table 2

The chemical composition of the constitutive phases of the program alloy after cold rolling and annealing at $800^{\circ} \mathrm{C}$ for $1-100 \mathrm{~h}$ (in. at.\%).

\begin{tabular}{lcccc}
\hline Element & $\mathrm{Ti}$ & $\mathrm{Cr}$ & $\mathrm{Nb}$ & $\mathrm{V}$ \\
\cline { 1 - 3 } Phase & & & & \\
\hline $1 \mathrm{~h}$ & & & & \\
Bcc matrix & 44.8 & 19.5 & 23.6 & 12.1 \\
Laves particles & 38.7 & 26.7 & 21.8 & 12.8 \\
$10 \mathrm{~h}$ & & & & \\
Bcc matrix & 46.4 & 18.4 & 23.1 & 12.1 \\
Laves particles & 36.4 & 28.2 & 21.9 & 13.5 \\
100 h & & & & \\
Bcc matrix & 47.3 & 17.7 & 23.3 & 11.7 \\
Laves particles & 36.1 & 28.7 & 22.1 & 13.1 \\
Actual alloy composition & 42.7 & 22.1 & 23.0 & 12.2 \\
\hline
\end{tabular}

in the microhardness and remained on the level of 454-469 HV.

Mechanical properties of the $\mathrm{Ti}_{1.89} \mathrm{CrNbV}_{0.56}$ alloy in the cold rolled condition $\left(\varepsilon_{\mathrm{th}}=80 \%\right)$ were evaluated using tensile testing (Fig. 10). The resulting stress-strain curve is shown in Fig. 10. The yield strength of the alloy was equal to $1020 \mathrm{MPa}$. The close values of the yield strength in the as-cast (Fig. 1d) and cold rolled conditions confirm weak work hardening during cold rolling (Fig. 10); note however that the compression testing can result in up to $\sim 18 \%$ higher strength of the same alloy [47]. After yielding, a pronounced but short strain hardening stage was observed. Such a strong strain hardening capacity of a heavily cold worked alloy is unexpected. The ultimate tensile strength of the alloy was $1535 \mathrm{MPa}$, while elongation to fracture was 3.5\%. More detailed investigation of the tensile behavior of the alloy depending on the microstructure is required to get better understanding of its mechanical behavior; such a study will be performed in future.
Annealing after cold rolling expectedly resulted in softening of the alloy (Fig. 11). The microhardness decreases become more pronounced (in comparison with the cold-rolled condition) with an increase in the annealing temperature from 800 to $1200^{\circ} \mathrm{C}$. To be more specific, after annealing for $10 \mathrm{~h}$ at $800{ }^{\circ} \mathrm{C}, 1000{ }^{\circ} \mathrm{C}$ or $1200{ }^{\circ} \mathrm{C}$ the respective microhardness values were $438 \mathrm{HV}, 376 \mathrm{HV}$, and $358 \mathrm{HV}$. The annealing duration had a rather weak effect on the microhardness; for instance; an increase in the annealing time from $1 \mathrm{~h}$ to $100 \mathrm{~h}$ at $800{ }^{\circ} \mathrm{C}$ resulted in a decrease in the microhardness value from $449 \mathrm{HV}$ to $433 \mathrm{HV}$.

\section{Discussion}

The obtained results have demonstrated that the program $\mathrm{Ti}_{1.89} \mathrm{CrNbV}_{0.56}$ alloy has low density $\left(6.17 \mathrm{~g} / \mathrm{cm}^{3}\right)$ together with high ductility in the as-cast condition. To the best of the authors' knowledge, only three RHEAs were processed by cold rolling: HfNbTaTiZr [19-22], $\mathrm{HfNb}_{0.18} \mathrm{Ta}_{0.18} \mathrm{Ti}_{1.27} \mathrm{Zr}$ [36] and $\mathrm{Hf}_{0.5} \mathrm{Nb}_{0.5} \mathrm{Ta}_{0.5} \mathrm{Ti}_{1.5} \mathrm{Zr}$ [48,49]. It should be noted that good ductility in compression/tension was reported for some other RHEAs, including HfNbTiZr [50], $\mathrm{Al}_{\mathrm{x}} \mathrm{HfNbTaTiZr}$ $(x=0-0.3)$ [51], HfMo ${ }_{x} N b T a T i Z r ~(x=0-0.75)$ [52]. However, these alloys have very similar chemical compositions to that of the HfNbTaTiZr (as well as $\mathrm{Hf}_{0.5} \mathrm{Nb}_{0.5} \mathrm{Ta}_{0.5} \mathrm{Ti}_{1.5} \mathrm{Zr}$ or $\mathrm{HfNb}_{0.18} \mathrm{Ta}_{0.18} \mathrm{Ti}_{1.27} \mathrm{Zr}$ alloys), in contrast to the program $\mathrm{Ti}_{1.89} \mathrm{CrNbV}_{0.56}$ alloy. Some characteristics of the introduced $\mathrm{Ti}_{1.89} \mathrm{CrNbV}_{0.56}$ alloy and $\mathrm{Hf}-\mathrm{Nb}-\mathrm{Ta}-\mathrm{Ti}-\mathrm{Zr}$ system alloys are shown in Table 2.

One can see from Table 4 that density of the $\mathrm{Ti}_{1.89} \mathrm{CrNbV}_{0.56}$ alloy is much lower than those of some Hf-Nb-Ta-Ti-Zr alloys; the difference is $20-60 \%$. Apparently, this is due to the absence of elements with high density like Hf $\left(13.31 \mathrm{~g} / \mathrm{cm}^{3}\right)$ or Ta $\left(16.69 \mathrm{~g} / \mathrm{cm}^{3}\right)$, and a high amount of low-density $\mathrm{Ti}\left(4.5 \mathrm{~g} / \mathrm{cm}^{3}\right)$. The $\mathrm{Ti}_{1.89} \mathrm{CrNbV}_{0.56}$ alloy has also a considerably higher average valence electron concentration parameter $\left(V E C=\Sigma c_{i} V E C_{i}\right.$, where $c_{i}$ and $V E C_{i}$ are the atomic concentration and 
A

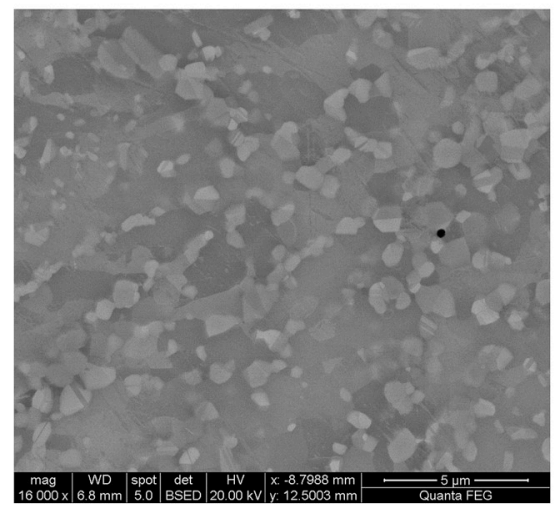

$\mathrm{B}$

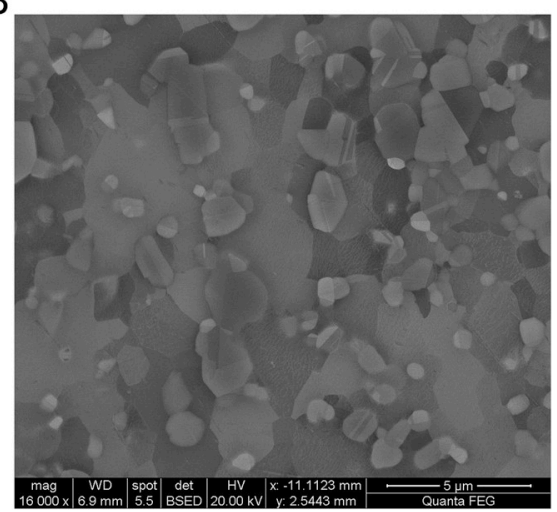

C

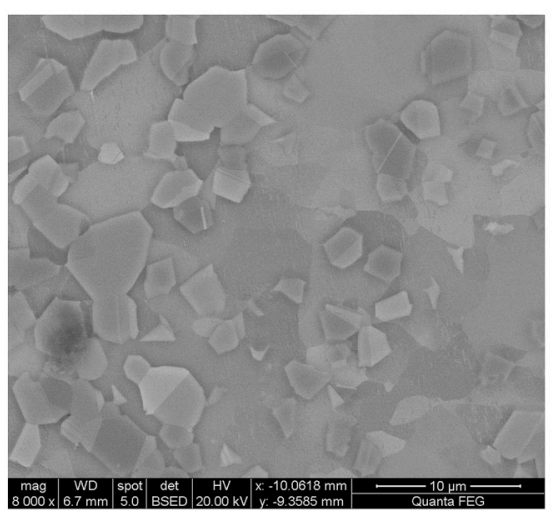

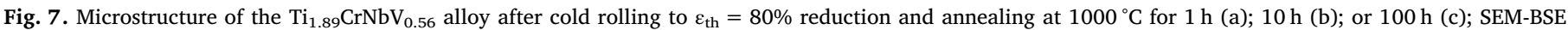
images.

Table 3

The chemical composition of the constitutive phases of the program alloy after cold rolling and annealing at $800^{\circ} \mathrm{C}$ for $1-100 \mathrm{~h}$.

\begin{tabular}{lllll}
\hline Element & $\mathrm{Ti}$ & $\mathrm{Cr}$ & $\mathrm{Nb}$ & $\mathrm{V}$ \\
\cline { 1 - 3 } Phase & & & & \\
\hline $1 \mathrm{~h}$ & & & & \\
Bcc matrix & 46.4 & 18.4 & 23.8 & 11.4 \\
Laves particles & 32.8 & 34.4 & 20.2 & 12.6 \\
$10 \mathrm{~h}$ & & & & \\
Bcc matrix & 46.8 & 17.8 & 23.5 & 11.9 \\
Laves particles & 21 & 47 & 19.6 & 12.4 \\
100 h & & & & \\
Bcc matrix & 53.4 & 10.8 & 24.2 & 11.6 \\
Laves particles & 18.8 & 49.2 & 18 & 14 \\
Actual alloy composition & 42.7 & 22.1 & 23.0 & 12.2 \\
\hline
\end{tabular}

the valence electron concentration of the $i$ element, respectively [53]). The VEC parameter is widely used for predicting the bcc to fcc transition in HEAs. In addition, it was recently proposed that ductile RHEAs should have $V E C \leq 4.4$ [48]. However, the program alloy also showed considerable ductility allowing cold rolling with high thickness reduction. This finding shows that the $V E C \leq 4.4$ condition is not necessary for obtaining ductile RHEAs.

Table 4 also compares the tensile properties of the introduced $\mathrm{Ti}_{1.89} \mathrm{CrNbV}_{0.56}$ alloy to other ductile RHEAs. Note that the alloys were examined in different conditions: cold rolled $\left(\mathrm{Ti}_{1.89} \mathrm{CrNbV}_{0.56}\right.$ $\left(\varepsilon_{\text {th }}=80 \%\right)$, HfNbTaTiZr $\left(\varepsilon_{\text {th }}=89 \%\right.$ [19])), recrystallized (HfNbTaTiZr (annealed at $1100^{\circ} \mathrm{C}$ for $2 \mathrm{~h}$, grain size of $38.4 \mu \mathrm{m}$ [19]), $\mathrm{HfNb}_{0.18} \mathrm{Ta}_{0.18} \mathrm{Ti}_{1.27} \mathrm{Zr}\left(900^{\circ} \mathrm{C}\right.$ for $0.5 \mathrm{~h}, 40 \mu \mathrm{m}$ [36])), or as-cast $\left(\mathrm{Hf}_{0.5} \mathrm{Nb}_{0.5} \mathrm{Ta}_{0.5} \mathrm{Ti}_{1.5} \mathrm{Zr}\right.$ [48]). Apparently, microstructure strongly affects mechanical behavior, one can compare the data for the cold rolled and recrystallized HfNbTaTiZr alloy for example. Cold worked alloy is much stronger but less ductile. Therefore, it is not surprising that the $\mathrm{Ti}_{1.89} \mathrm{CrNbV}_{0.56}$ is less ductile than the other RHEAs in the recrystallized or as-cast condition. Meanwhile, the ductility of the $\mathrm{Ti}_{1.89} \mathrm{CrNbV}_{0.56}$ alloy is comparable with the ductility of the HfNbTaTiZr alloy in cold rolled condition: $3.5 \%$ and $5.0 \%$, respectively. It is reasonable to suggest that proper heat treatment (i.e. recrystallization) can improve the alloy ductility further. The ultimate tensile strength of the $\mathrm{Ti}_{1.89} \mathrm{CrNbV}_{0.56}$ alloy is much higher than that of the rest of the alloys. Due to low density, the specific properties of the alloy are even more impressive. For example, the specific UTS of the $\mathrm{Ti}_{1.89} \mathrm{CrNbV}_{0.56}$ alloy is almost twice higher than that of the cold rolled HfNbTaTiZr (Table 4).

Microstructure evolution of the $\mathrm{Ti}_{1.89} \mathrm{CrNbV}_{0.56}$ alloy during cold rolling (Figs. 2-4) was quite typical of metallic materials. In particular an increase in dislocation density and shear banding have already been reported for the equiatomic HfNbTaTiZr alloy [19-21,23]. However, the formation of deformation-induced high-angle boundaries forming lens-shaped areas deserves additional consideration. Morphologically, these areas look like deformation twins; yet the misorientation of their boundaries (see inserts in Fig. 2b and c) is much lower than the mis-

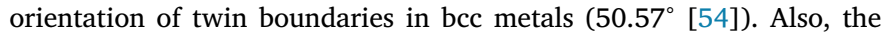
misorientation of the observed high-angle boundaries increased with the strain. Similar microstructural features (having a lens-like shape and grain misorientation around $20^{\circ}$ ) have already been observed in beta (bcc) titanium alloys and were attributed to the formation of kink bands [55,56]. Given the similarity of both the crystal structure and chemical composition (due to a high amount of $\mathrm{Ti}$ in the program alloy), it can be suggested that the observed lens-shaped areas are the kink bands. However this question deserves further detailed investigation.

Annealing after cold rolling has resulted in the phase transformations; heat treatment at a temperature of $1000{ }^{\circ} \mathrm{C}$ and below resulted in 
A

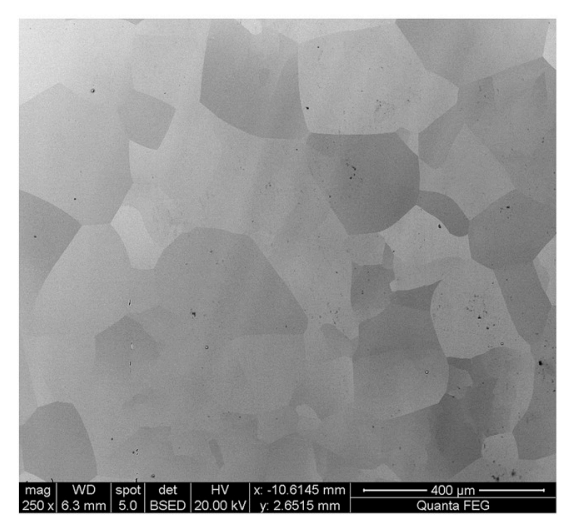

B

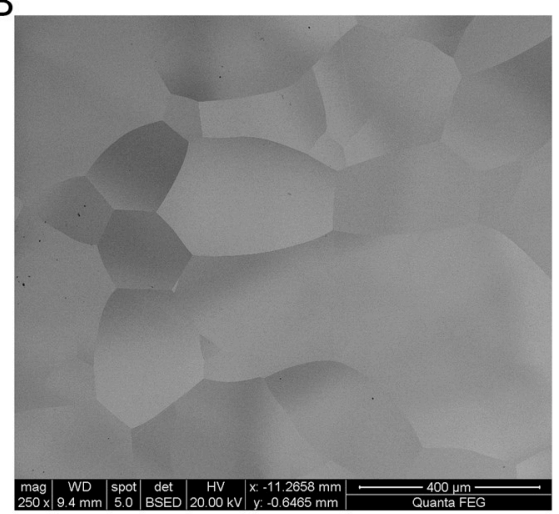

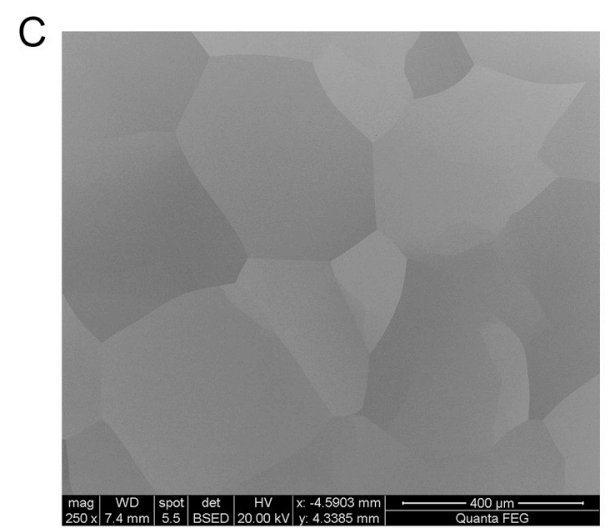

Fig. 8. Microstructure of the $\mathrm{Ti}_{1.89} \mathrm{CrNbV}_{0.56}$ alloy after cold rolling to $\varepsilon_{\text {th }}=80 \%$ and annealing at $1200{ }^{\circ} \mathrm{C}$ for $1 \mathrm{~h}$ (a); $10 \mathrm{~h}$ (b); or $25 \mathrm{~h}$ (c); $\mathrm{SEM}-\mathrm{BSE}$ images.

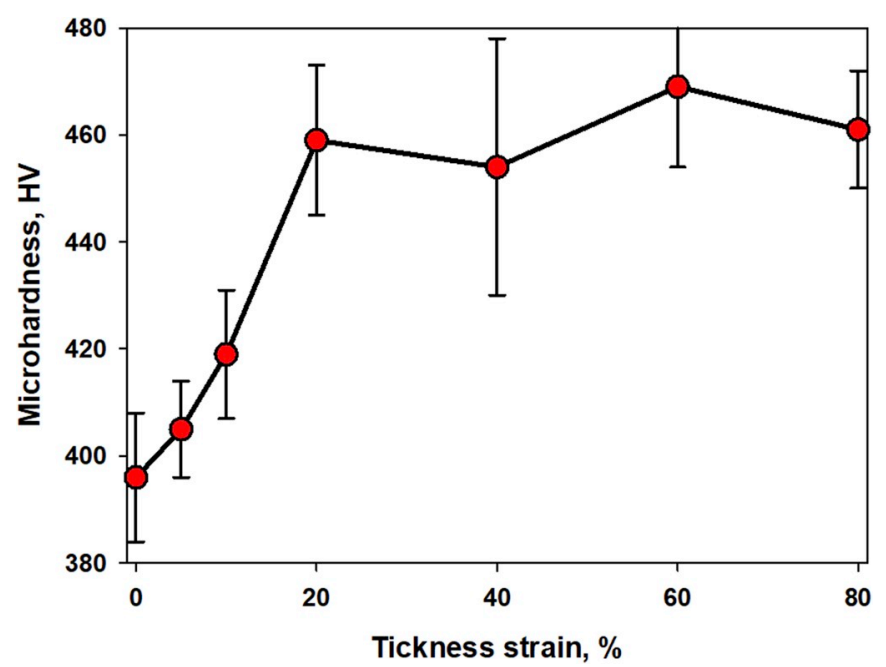

Fig. 9. Dependence of microhardness of the program $\mathrm{Ti}_{1.89} \mathrm{CrNbV}_{0.56}$ alloy on thickness strain.

the C15 Laves phase particles precipitation (Figs. 5-7). After annealing at a higher temperature of $1200^{\circ} \mathrm{C}$, the single-phase bcc structure was observed (Fig. 8). Fig. 12 shows the dependence of the equilibrium phase fractions on temperature for the program alloy obtained using a Thermo-Calc software. The alloy solidifies through a bcc solid solution phase with a nominal composition. The alloy maintains the single phase structure till $\sim 1000{ }^{\circ} \mathrm{C}$; at lower temperatures, an fcc (C15) Laves phase with the chemical composition close to that of the binary $\mathrm{Cr}_{2} \mathrm{Nb}$ compound precipitates. In turn, the bcc phase becomes depleted of $\mathrm{Cr}$ and $\mathrm{Nb}$. The fraction of the Laves phase gradually increases with a decrease in temperature. Finally, at $\sim 600^{\circ} \mathrm{C}$, a Ti-rich phase with a hexagonal

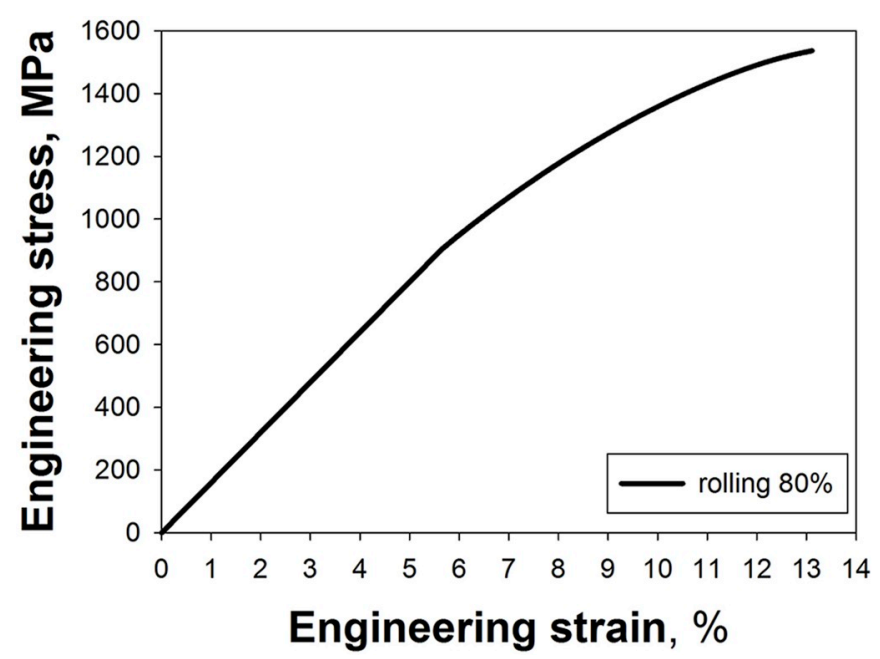

Fig. 10. Tensile stress-strain curve the $\mathrm{Ti}_{1.89} \mathrm{CrNbV}_{0.56}$ alloy after cold rolling to $\varepsilon_{\text {th }}=80 \%$.

close-packed (HCP) structure forms.

The observed phases (the single bcc phase in the as-cast condition and after annealing at $1200{ }^{\circ} \mathrm{C}$ and the bcc + Laves mixture after annealing at $800-1000^{\circ} \mathrm{C}$ ) agree reasonably well with those predicted by the phase diagram. However, there are some discrepancies between the experimental data and predictions. For example, the experimental fraction of the Laves phase after annealing at $1000{ }^{\circ} \mathrm{C}(0.25-0.36)$ was an order of magnitude higher than the predicted equilibrium fraction at the corresponding temperature $(\approx 0.02)$. Apparently, this difference is a result of an incorrectly predicted solvus temperature of the Laves phase due to the imperfection of the used database [3,57]. In addition, higher 


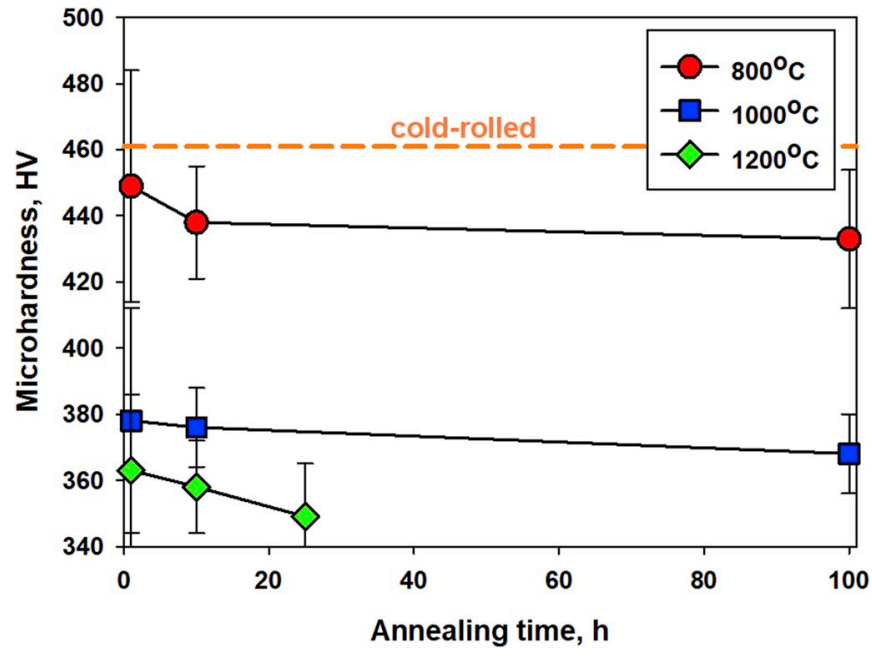

Fig. 11. Dependence of microhardness of the $\mathrm{Ti}_{1.89} \mathrm{CrNbV}_{0.56}$ alloy on annealing temperature and time. Orange dashed line shows microhardness of the alloy after cold rolling to $\varepsilon_{\text {th }}=80 \%$. (For interpretation of the references to colour in this figure legend, the reader is referred to the Web version of this article.)

diffusion rate at higher temperatures resulted in faster attaining of equilibrium (or nearly equilibrium) fraction of the Laves phase particles.

Annealing was also associated with recovery (at $800^{\circ} \mathrm{C}$ ) or recrystallization (at 1000 or $1200^{\circ} \mathrm{C}$ ) in the bcc phase (Figs. 6-8). Annealing in the single bcc phase field at $1200^{\circ} \mathrm{C}$ resulted in coarse grains $(\sim 150-200 \mu \mathrm{m}$, Fig. 8$)$ due to the high annealing temperature and the absence of any obstacles for boundaries migration. A decrease in the annealing temperature to $1000^{\circ} \mathrm{C}$ and precipitation of a large amount of fine Laves phase particles most likely strongly impede the grain boundaries motion and restrict grain growth via the well-known Zener drag mechanism $[58,59]$ thereby significantly reducing the size of recrystallized grains to $\sim 2-5 \mu \mathrm{m}$ (Fig. 7 ). The Zener-limiting grain size can be calculated using the following equation [60]:

$D_{Z}=a \frac{2 d}{3 F_{v}}$

where $D_{z}$ is a grain size, $\alpha$ is a scaling factor, $d$ and $F_{v}$ are a size and fraction of particles, respectively. A relationship between the size/ fraction ratio $\left(D_{\text {Laves }} / F_{\text {Laves }}\right)$ of the Laves phase particles and the recrystallized bcc grain size $\left(D_{b c c}\right)$ is plotted in Fig. 13. One can see a linear character of the $D_{\text {Laves }} / F_{\text {Laves }}$ and $D_{b c c}$ relationship. This finding indicates that indeed Zener pinning by the Laves phase particles limits grain growth in the program alloy during annealing at $1000^{\circ} \mathrm{C}$; similar phenomena has already been reported for some transition metals HEAs [61,62].

Changes in the microstructure apparently affect mechanical properties, e.g. microhardness (Figs. 9 and 11). In general, these changes are well anticipated: the alloy became harder during rolling and softened after annealing. Work hardening can be mostly attributed to an increase in dislocation density (Fig. 3), an additional contribution can be provided by the formation of new deformation-induced boundaries and dislocation arrays (Figs. 2 and 4). However, while the deformation (sub)structure continuously developed with an increase in rolling stain (Fig. 2), the hardness increase saturated already after $20 \%$ reduction. Note that a qualitatively similar strain hardening behavior during cold rolling has been reported for some other RHEAs with the bcc structure (HfNbTaTiZr, for example [20]) or beta (bcc) titanium alloys (gum metals, for example [63]). Such a behavior can be associated with the significant microstructure inhomogeneity during rolling (Fig. 2e) and distinctively different local mechanical properties of areas with different imparted strain levels. Indeed, nanohardness measurements have revealed that the hardness varied from 440 to $480 \mathrm{HV}$ for the least deformed regions (the nanohardness of the initial (as-cast) condition was $420 \mathrm{HV}$ ) to $540-600 \mathrm{HV}$ in the shear bands. Most probably, the absence of noticeable strain hardening at late stages of deformation can be associated with gradual involvement of the less-strained areas into deformation.

The presence of weakly-deformed regions, as well as possible relaxation of stresses after rolling, is most likely a reason for the prominent strain hardening capacity of the cold rolled alloy during the tensile test (Fig. 10). Note that the hardening stage during tension was very short (uniform elongation was only $3.5 \%$ ); similarly, short $\left(\varepsilon_{\text {th }} \leq 20 \%\right)$ strain hardening stage was observed during rolling (Fig. 9). However a "hard" scheme of deformation during tension and limited strain hardening resulted in a short stage of uniform straining, rapid strain localization and fracture.

Annealing after cold rolling resulted in softening of the alloy obviously due to the development of recovery or recrystallization in the bcc matrix. It should be noted that the Laves phase particles precipitation apparently did not result in pronounced strengthening of the alloy (Fig. 11). Thus annealing at $1000^{\circ} \mathrm{C}$ (yielded the fine-grained recrystallized bcc matrix with the Laves phase particles fraction of 0.36 ) resulted in even slightly smaller hardness than that of the coarsegrained as-cast condition: $396 \mathrm{HV} v$ s. $368-378 \mathrm{HV}$, respectively. This finding can be partially associated with the chemical composition variation in the bcc phase after annealing, i.e. depletion in $\mathrm{Cr}$ due to its partitioning in the Laves phase, and associated changes in solid solution strengthening.

The precise models for solid solution strengthening in multicomponent HEAs are currently under development since the classic models can be applied for dilute alloys only [2,27,30,64,65]. In any case the solid solution strengthening depends on the atom size misfit and the modulus misfit between the solute and solvent atoms (meanwhile identification of the solvent and solute species in close to equiatomic HEAs is complicated) [27]. The constitutive elements of the program alloy have relatively close atomic radii in a range of 126-147 p.m. Therefore, the lattice distortion is not expected to be high in any possible atomic pair. However, the shear modulus of $\mathrm{Cr}(110 \mathrm{GPa})$ is noticeably higher than that for the other elements $(38-47 \mathrm{GPa})$.

Table 4

Density, valence electron concentration (VEC), and tensile mechanical properties, namely yield strength (YS), specifiv yield strength (SYS), ultimate tensile strength (UTS), specific ultimate tensile strength (SUTS), and elongation to fracture (EF), of the program $\mathrm{Ti}_{1.89} \mathrm{CrNbV}_{0.56}$ alloy in comparison with those of HfNbTaTiZr, $\mathrm{Hf}_{0.5} \mathrm{Nb}_{0.5} \mathrm{Ta}_{0.5} \mathrm{Ti}_{1.5} \mathrm{Zr}$ or $\mathrm{HfNb}_{0.18} \mathrm{Ta}_{0.18} \mathrm{Ti}_{1.27} \mathrm{Zr}$ alloys.

\begin{tabular}{|c|c|c|c|c|c|c|c|c|c|}
\hline \multirow[t]{2}{*}{ Alloy } & \multirow[t]{2}{*}{ Density, $\mathrm{g} / \mathrm{cm}^{3}$} & \multirow[t]{2}{*}{$V E C$} & \multicolumn{6}{|c|}{ Mechanical properties } & \multirow[t]{2}{*}{ Reference } \\
\hline & & & Condition & YS, MPa & SYS, $\mathrm{kPa} \times \mathrm{m}^{3} \times \mathrm{kg}^{-1}$ & UTS, MPa & SUTS, $\mathrm{kPa} \times \mathrm{m}^{3} \times \mathrm{kg}^{-1}$ & $\mathrm{EF}, \%$ & \\
\hline $\mathrm{Ti}_{1.89} \mathrm{CrNbV}_{0.56}$ & 6.17 & 4.8 & Cold-worked & 1020 & 165.3 & 1535 & 248.0 & 3.5 & This work \\
\hline \multirow[t]{2}{*}{ HfNbTaTiZr } & 9.89 & 4.4 & Cold-worked & 1438 & 145.4 & 1495 & 151.2 & 5.0 & {$[19,27]$} \\
\hline & & & Recrystallized & 1114 & 112.6 & 1168 & 118.1 & 12.2 & \\
\hline $\mathrm{Hf}_{0.5} \mathrm{Nb}_{0.5} \mathrm{Ta}_{0.5} \mathrm{Ti}_{1.5} \mathrm{Zr}$ & 8.13 & 4.25 & As-cast & 903 & 111.1 & 990 & 121.8 & 18.8 & [48] \\
\hline $\mathrm{HfNb}_{0.18} \mathrm{Ta}_{0.18} \mathrm{Ti}_{1.27} \mathrm{Zr}$ & 8.48 & 4.1 & Recrystallized & 540 & 63.7 & 995 & 117.3 & 23.0 & [36] \\
\hline
\end{tabular}




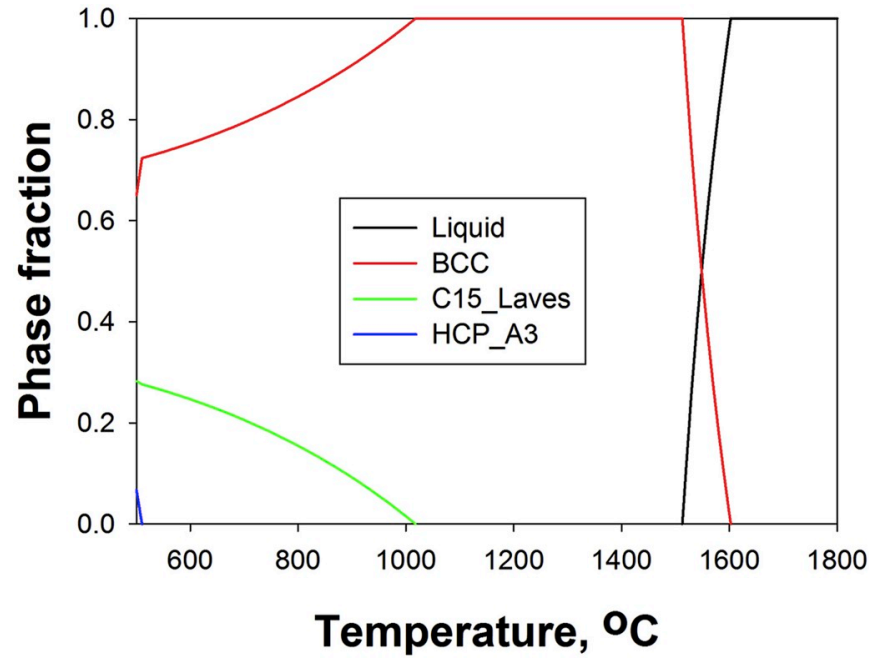

Fig. 12. Equilibrium phase diagram of the $\mathrm{Ti}_{1.89} \mathrm{CrNbV}_{0.56}$ alloy produced by Thermo-Calc software.

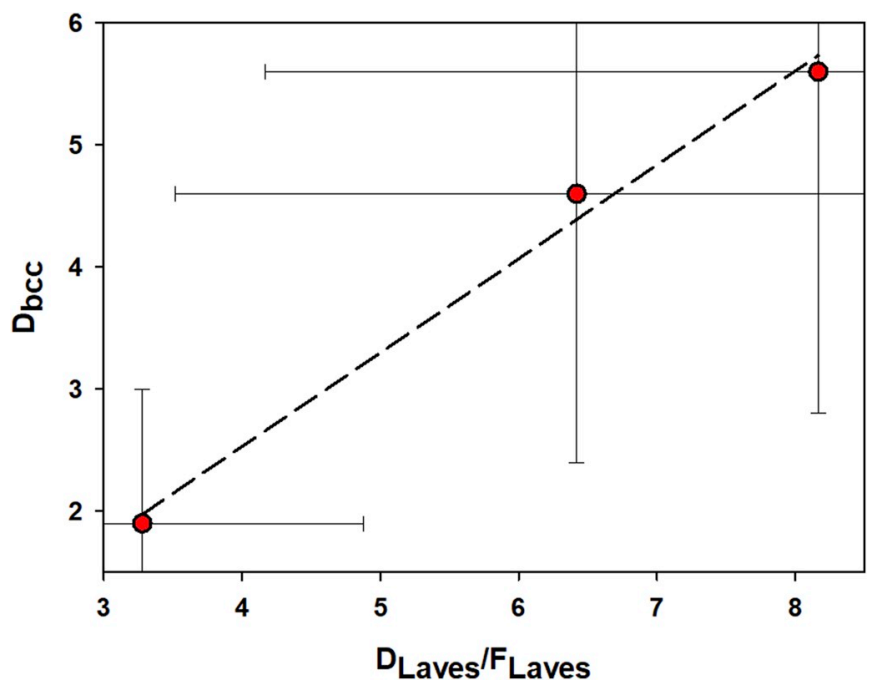

Fig. 13. Dependence of the bcc grain size on the ratio between the size and fraction of the Laves phase particles in the $\mathrm{Ti}_{1.89} \mathrm{CrNbV}_{0.56}$ alloy after cold rolling and annealing at $1000^{\circ} \mathrm{C}$.

Therefore, strong modulus distortions are expected around $\mathrm{Cr}$ atoms that can generate the strongest solid solution strengthening. The depletion of bcc solid solution in $\mathrm{Cr}$ (22.1 at.\% in the as-cast condition and 10.8 at.\% after annealing at $1000^{\circ} \mathrm{C}$ for $100 \mathrm{~h}$ (Tables 1 and 2)) is expected to lower the modulus misfit and the solid solution stengthening. Thus, the decreased $\mathrm{Cr}$ concentration in the bcc solid solution can result in the lower hardness of the alloy (Fig. 11).

Besides, the as-cast alloy have dendritic segregations (Fig. 1b) that can also have a positive effect on strength in comparison with the homogenios elemental distribution after annealing (Fig. 7 for example) [47]. Finally, Fig. 11 suggests relative "softness" of the Laves phase particles at room temperature, as it was earlier reported for some similar RHEAs with B2/Laves phase structures [37]. Nevertheless, the ordered B2 phase in Ref. [37] was expected to be much harder than the disordered bcc solid solution in the studied alloy. Therefore, nanohardness tests of the program alloy were performed after annealing at $1000^{\circ} \mathrm{C}$ for $100 \mathrm{~h}$. The hardness values were found to be $390-420 \mathrm{HV}$ for the bcc phase and 360-400 HV for the Laves phase particles, respectively. Although the obtained values for different phases overlap, the Laves phase particles were somewhat softer than the bcc matrix. The relative "softness" of the Laves particles can be attributed to their complex chemistry (Tables 2 and 3); it was earlier revealed that deviations from the stoichiometry and/or addition of other elements can decrease hardness of the binary $\mathrm{AB}_{2}$ Laves phase [66-68]. However, potentially the Laves phase particles precipitation can have a positive effect on high-temperature mechanical properties of the alloy. Further studies in this direction will be performed in the future.

\section{Conclusions}

In this work, microstructure and microhardness evolution during cold rolling to $\varepsilon_{\text {th }}=80 \%$ thickness strain and subsequent annealing at $800-1200{ }^{\circ} \mathrm{C}$ for $1-100 \mathrm{~h}$ of the new $\mathrm{Ti}_{1.89} \mathrm{CrNbV}_{0.56}$ refractory high entropy alloy were examined and following conclusions were drawn:

1) In the as-cast condition, the alloy had the coarse-grained singlephase bcc structure. The density of the alloy was $6.17 \mathrm{~g} / \mathrm{cm}^{3}$. Compression tests have revealed high ductility of the alloy enabling cold rolling to a high thickness strain $\left(\varepsilon_{\text {th }}=80 \%\right)$. The compression yield strength of the alloy was $990 \mathrm{MPa}$.

2) Cold rolling was associated with the flattening of the initial coarse grains, development of dislocation substructure, and formation of kink and shear bands. The microstructure of the alloy remained highly heterogeneous even after rolling to $\varepsilon_{\text {th }}=80 \%$. The microhardness of the alloy increased from $396 \mathrm{HV}$ in the as-cast condition to $454-469 \mathrm{HV}$ after rolling to $\varepsilon_{\text {th }}=20-80 \%$. After cold rolling to $\varepsilon_{\text {th }}=80 \%$ the alloy had yield strength of $1020 \mathrm{MPa}$, ultimate tensile strength of $1535 \mathrm{MPa}$, and elongation to fracture of $3.5 \%$.

3) Annealing resulted in (i) precipitation of the Cr-rich $\mathrm{C} 15$ Laves phase particles at $800^{\circ} \mathrm{C}$ or $1000^{\circ} \mathrm{C}$ and (ii) recovery (at $800{ }^{\circ} \mathrm{C}$ ) or recrystallization (at $1000^{\circ} \mathrm{C}$ or $1200{ }^{\circ} \mathrm{C}$ ) of the bcc matrix. Precipitation of the Laves phase particles was found to be in reasonable agreement with the equilibrium phase diagram produced using the Thermo-Calc software. The size of the recrystallized bcc grains was $\sim 2-5 \mu \mathrm{m}$ and $\sim 150-200 \mu \mathrm{m}$ after annealing at $1000^{\circ} \mathrm{C}$ or $1200{ }^{\circ} \mathrm{C}$, respectively. Much finer grain size at a lower temperature was attributed to the pinning effect of the Laves phase particles. An increase in the annealing temperature resulted in a gradual increase in the microhardness from $\sim 430$ to $450 \mathrm{HV}$ at $800^{\circ} \mathrm{C}$ to $\sim 340-360 \mathrm{HV}$ at $1200^{\circ} \mathrm{C}$.

\section{Data availability statement}

The raw/processed data required to reproduce these findings cannot be shared at this time as the data also forms part of an ongoing study.

\section{Declaration of competing interest}

None.

\section{Acknowledgments}

The authors gratefully acknowledge the financial support from the Russian Foundation for Basic Research (Grant No. 18-38-20013). The authors are grateful to the personnel of the Joint Research Center, «Technology and Materials», Belgorod State National Research University, for their assistance with the instrumental analysis.

\section{References}

[1] J.H. Perepezko, Materials science. The hotter the engine, the better, Science 326 (2009) 1068-1069, https://doi.org/10.1126/science.1179327.

[2] D.B. Miracle, O.N. Senkov, A critical review of high entropy alloys and related concepts, Acta Mater. 122 (2017) 448-511, https://doi.org/10.1016/j.actamat. 2016.08.081.

[3] O.N. Senkov, D.B. Miracle, K.J. Chaput, J.-P. Couzinie, Development and exploration of refractory high entropy alloys-a review, J. Mater. Res. 33 (2018) 3092-3128, https://doi.org/10.1557/jmr.2018.153. 
[4] S. Gorsse, D.B. Miracle, O.N. Senkov, Mapping the world of complex concentrated alloys, Acta Mater. 135 (2017) 177-187, https://doi.org/10.1016/j.actamat.2017. 06.027.

[5] O.N. Senkov, G.B. Wilks, D.B. Miracle, C.P. Chuang, P.K. Liaw, Refractory highentropy alloys, Intermetallics 18 (2010) 1758-1765, https://doi.org/10.1016/j. intermet.2010.05.014.

[6] O.N. Senkov, G.B. Wilks, J.M. Scott, D.B. Miracle, Mechanical properties of Nb 25Mo 25Ta 25W 25 and V 20Nb 20Mo 20Ta 20W 20 refractory high entropy alloys, Intermetallics 19 (2011) 698-706, https://doi.org/10.1016/j.intermet.2011.01. 004.

[7] N.D. Stepanov, D.G. Shaysultanov, G.A. Salishchev, M.A. Tikhonovsky, Structure and mechanical properties of a light-weight AlNbTiV high entropy alloy, Mater. Lett. 142 (2015) 153-155, https://doi.org/10.1016/j.matlet.2014.11.162.

[8] N.D. Stepanov, N. Yu Yurchenko, D.G. Shaysultanov, G.A. Salishchev, M.A. Tikhonovsky, Effect of Al on structure and mechanical properties of AlxNbTiVZr ( $\mathrm{x}=0,0.5,1,1.5)$ high entropy alloys, Mater. Sci. Technol. 31 (2015) 1184-1193, https://doi.org/10.1179/1743284715Y.0000000032.

[9] O.N. Senkov, C. Woodward, D.B. Miracle, Microstructure and properties of aluminum-containing refractory high-entropy alloys, JOM 66 (2014) 2030-2042, https://doi.org/10.1007/s11837-014-1066-0.

[10] O.N. Senkov, S.V. Senkova, C.F. Woodward, Effect of aluminum on the microstructure and properties of two refractory high-entropy alloys, Acta Mater. 68 (2014) 214-228, https://doi.org/10.1016/j.actamat.2014.01.029.

[11] O.N. Senkov, D. Isheim, D.N. Seidman, A.L. Pilchak, Development of a refractory high entropy superalloy, Entropy 18 (2016), https://doi.org/10.3390/e18030102.

[12] N.Y. Yurchenko, N.D. Stepanov, D.G. Shaysultanov, M.A. Tikhonovsky, G.A. Salishchev, Effect of Al content on structure and mechanical properties of the $\mathrm{Al}_{\mathrm{x}} \operatorname{CrNbTiVZr}(\mathrm{x}=0 ; 0.25 ; 0.5 ; 1)$ high-entropy alloys, Mater. Char. (2016), https://doi.org/10.1016/j.matchar.2016.09.039.

[13] N.D. Stepanov, N.Y. Yurchenko, D.V. Skibin, M.A. Tikhonovsky, G.A. Salishchev, Structure and mechanical properties of the AlCrxNbTiV $(\mathrm{x}=0,0.5,1,1.5)$ high entropy alloys, J. Alloy. Comp. 652 (2015) 266-280, https://doi.org/10.1016/j. jallcom.2015.08.224.

[14] C.C. Juan, M.H. Tsai, C.W. Tsai, C.M. Lin, W.R. Wang, C.C. Yang, S.K. Chen, S.J. Lin, J.W. Yeh, Enhanced mechanical properties of HfMoTaTiZr and HfMoNbTaTiZr refractory high-entropy alloys, Intermetallics 62 (2015), https://doi.org/10.1016/j. intermet.2015.03.013.

[15] Y. Chen, Y. Li, X. Cheng, Z. Xu, C. Wu, B. Cheng, M. Wang, Interstitial strengthening of refractory ZrTiHfNb0.5Ta0.5Ox $(\mathrm{x}=0.05,0.1,0.2)$ high-entropy alloys, Mater. Lett. 228 (2018) 145-147, https://doi.org/10.1016/J.MATLET.2018.05.123.

[16] Y. Chen, Y. Li, X. Cheng, C. Wu, B. Cheng, Z. Xu, Y. Chen, Y. Li, X. Cheng, C. Wu, $\mathrm{B}$. Cheng, $\mathrm{Z}$. Xu, The microstructure and mechanical properties of refractory highentropy alloys with high plasticity, Materials 11 (2018) 208, https://doi.org/10. 3390/ma11020208.

[17] O.N. Senkov, S.V. Senkova, C. Woodward, D.B. Miracle, Low-density, refractory multi-principal element alloys of the Cr-Nb-Ti-V-Zr system: microstructure and phase analysis, Acta Mater. 61 (2013) 1545-1557, https://doi.org/10.1016/j. actamat.2012.11.032.

[18] O.N. Senkov, S. V Senkova, D.B. Miracle, C. Woodward, Mechanical properties of low-density, refractory multi-principal element alloys of the $\mathrm{Cr}-\mathrm{Nb}-\mathrm{Ti}-\mathrm{V}-\mathrm{Zr}$ system, Mater. Sci. Eng. A 565 (2013) 51-62, https://doi.org/10.1016/j.msea. 2012.12.018.

[19] O.N. Senkov, A.L. Pilchak, S.L. Semiatin, Effect of cold deformation and annealing on the microstructure and tensile properties of a HfNbTaTiZr refractory high entropy alloy, Metall. Mater. Trans. A (2018) 1-17, https://doi.org/10.1007/s11661018-4646-8.

[20] O.N. Senkov, S.L. Semiatin, Microstructure and properties of a refractory high-entropy alloy after cold working, J. Alloy. Comp. 649 (2015) 1110-1123, https://doi. org/10.1016/j.jallcom.2015.07.209.

[21] W. Wu, S. Ni, Y. Liu, M. Song, Effects of cold rolling and subsequent annealing on the microstructure of a HfNbTaTiZr high-entropy alloy, J. Mater. Res. 31 (2016) 3815-3823, https://doi.org/10.1557/jmr.2016.445.

[22] C.C. Juan, M.H. Tsai, C.W. Tsai, W.L. Hsu, C.M. Lin, S.K. Chen, S.J. Lin, J.W. Yeh, Simultaneously increasing the strength and ductility of a refractory high-entropy alloy via grain refining, Mater. Lett. 184 (2016) 200-203, https://doi.org/10.1016/ j.matlet.2016.08.060.

[23] G. Dirras, J. Gubicza, A. Heczel, L. Lilensten, J.-P. Couzinié, L. Perrière, I. Guillot, A. Hocini, Microstructural investigation of plastically deformed Ti20Zr20Hf20Nb20Ta20 high entropy alloy by X-ray diffraction and transmission electron microscopy, Mater. Char. 108 (2015) 1-7, https://doi.org/10.1016/j. matchar.2015.08.007.

[24] B. Schuh, B. Völker, J. Todt, N. Schell, L. Perriere, J. Li, J.P. Couzinié, A. Hohenwarter, Thermodynamic instability of a nanocrystalline, single-phase TiZrNbHfTa alloy and its impact on the mechanical properties, Acta Mater. 142 (2017) 201-212, https://doi.org/10.1016/j.actamat.2017.09.035.

[25] L. Lilensten, J.-P. Couzinie, L. Perriere, A. Hocini, C. Keller, G. Dirras, I. Guillot, L. Lilensten, J.P. Couzinié, L. Perrière, A. Hocini, C. Keller, G. Dirras, I. Guillot, Study of a bcc multi-principal element alloy: tensile and simple shear properties and underlying deformation mechanisms, Acta Mater. 142 (2018) 131-141, https://doi. org/10.1016/j.actamat.2017.09.062.

[26] O.N. Senkov, J.M. Scott, S.V. Senkova, F. Meisenkothen, D.B. Miracle, C.F. Woodward, Microstructure and elevated temperature properties of a refractory TaNbHfZrTi alloy, J. Mater. Sci. 47 (2012) 4062-4074, https://doi.org/10.1007/ s10853-012-6260-2.

[27] O.N. Senkov, J.M. Scott, S.V. Senkova, D.B. Miracle, C.F. Woodward, Microstructure and room temperature properties of a high-entropy TaNbHfZrT alloy, J. Alloy. Comp. 509 (2011) 6043-6048, https://doi.org/10.1016/j.jallcom. 2011.02.171.

[28] M.J. Yao, K.G. Pradeep, C.C. Tasan, D. Raabe, A novel, single phase, non-equiatomic FeMnNiCoCr high-entropy alloy with exceptional phase stability and tensile ductility, Scr. Mater. (2014) 72-73, https://doi.org/10.1016/j.scriptamat.2013.09. 030 .

[29] Y. Zhou, D. Zhou, X. Jin, L. Zhang, X. Du, B. Li, Design of non-equiatomic mediumentropy alloys, Sci. Rep. 8 (2018) 1236, https://doi.org/10.1038/s41598-01819449-0.

[30] N.D. Stepanov, D.G. Shaysultanov, M.A. Tikhonovsky, G.A. Salishchev, Tensile properties of the Cr-Fe-Ni-Mn non-equiatomic multicomponent alloys with different Cr contents, Mater. Des. 87 (2015) 60-65, https://doi.org/10.1016/j.matdes.2015. 08.007.

[31] K.G. Pradeep, C.C. Tasan, M.J. Yao, Y. Deng, H. Springer, D. Raabe, Non-equiatomic high entropy alloys: approach towards rapid alloy screening and property-oriented design, Mater. Sci. Eng. A 648 (2015), https://doi.org/10.1016/j.msea.2015.09. 010 .

[32] H.T. Jeong, W.J. Kim, Microstructures and mechanical properties of the nonequiatomic FeMnNiCoCr high entropy alloy processed by differential speed rolling, Mater. Sci. Eng. A 727 (2018) 38-42, https://doi.org/10.1016/J.MSEA.2018.04. 106.

[33] Z. Li, K.G. Pradeep, Y. Deng, D. Raabe, C.C. Tasan, Metastable high-entropy dualphase alloys overcome the strength-ductility trade-off, Nature 534 (2016), https:// doi.org/10.1038/nature17981.

[34] Z. Li, C.C. Tasan, H. Springer, B. Gault, D. Raabe, Interstitial atoms enable joint twinning and transformation induced plasticity in strong and ductile high-entropy alloys, Sci. Rep. 7 (2017) 40704, https://doi.org/10.1038/srep40704.

[35] D.G. Shaysultanov, G.A. Salishchev, Y.V. Ivanisenko, S.V. Zherebtsov, M.A. Tikhonovsky, N.D. Stepanov, Novel Fe36Mn21Cr18Ni15Al10high entropy alloy with bcc/B2 dual-phase structure, J. Alloy. Comp. 705 (2017) 756-763, https://doi.org/10.1016/j.jallcom.2017.02.211.

[36] L. Lilensten, J.-P. Couzinié, J. Bourgon, L. Perrière, G. Dirras, F. Prima, I. Guillot, Design and tensile properties of a bcc Ti-rich high-entropy alloy with transformation-induced plasticity, Mater. Res. Lett. 5 (2017) 110-116, https://doi.org/10. 1080/21663831.2016.1221861.

[37] N.Y. Yurchenko, N.D. Stepanov, S.V. Zherebtsov, M.A. Tikhonovsky, G.A. Salishchev, Structure and mechanical properties of B2 ordered refractory AlNbTiVZrx (x = 0-1.5) high-entropy alloys, Mater. Sci. Eng. A 704 (2017) 82-90, https://doi.org/10.1016/j.msea.2017.08.019.

[38] N.Y. Yurchenko, N.D. Stepanov, A.O. Gridneva, M.V. Mishunin, G.A. Salishchev, S.V. Zherebtsov, Effect of $\mathrm{Cr}$ and $\mathrm{Zr}$ on phase stability of refractory Al-Cr-Nb-Ti-V-Zr high-entropy alloys, J. Alloy. Comp. (2018), https://doi.org/10.1016/j.jallcom. 2018.05.099.

[39] N.Y. Yurchenko, N.D. Stepanov, D.G. Shaysultanov, M.A. Tikhonovsky, G.A. Salishchev, Effect of Al content on structure and mechanical properties of the AlxCrNbTiVZr (x?? = ??0; 0.25; 0.5; 1) high-entropy alloys, Mater. Char. 121 (2016) 125-134, https://doi.org/10.1016/j.matchar.2016.09.039.

[40] N. Yurchenko, N. Stepanov, G. Salishchev, Laves-phase formation criterion for highentropy alloys, Mater. Sci. Technol. 33 (2017) 17-22, https://doi.org/10.1080/ 02670836.2016.1153277.

[41] N.D. Stepanov, N.Y. Yurchenko, A.O. Gridneva, S.V. Zherebtsov, Y.V. Ivanisenko, G.A. Salishchev, Structure and hardness of B2 ordered refractory AlNbTiVZr0.5 high entropy alloy after high-pressure torsion, Mater. Sci. Eng. A 716 (2018) 308-315, https://doi.org/10.1016/J.MSEA.2018.01.061.

[42] N. Yurchenko, E. Panina, S. Zherebtsov, G. Salishchev, N. Stepanov, N. Yurchenko, E. Panina, S. Zherebtsov, G. Salishchev, N. Stepanov, Oxidation behavior of refractory AlNbTiVZr0.25 high-entropy alloy, Materials 11 (2018) 2526, https://doi org $/ 10.3390 /$ ma11122526.

[43] N.D. Stepanov, N.Y. Yurchenko, E.S. Panina, M.A. Tikhonovsky, S.V. Zherebtsov, Precipitation-strengthened refractory Al0, 5CrNbTi2V0.5 High Entropy Alloy, Elsevier, 2017, https://doi.org/10.1016/j.matlet.2016.11.030.

[44] A.P. Zhilyaev, I. Shakhova, A. Morozova, A. Belyakov, R. Kaibyshev, Grain refinement kinetics and strengthening mechanisms in $\mathrm{Cu}-0.3 \mathrm{Cr}-0.5 \mathrm{Zr}$ alloy subjected to intense plastic deformation, Mater. Sci. Eng. A 654 (2016) 131-142, https://doi. org $/ 10.1016 / J . M S E A .2015 .12 .038$.

[45] W.C. Oliver, G.M. Pharr, Measurement of hardness and elastic modulus by instrumented indentation: advances in understanding and refinements to methodology, J. Mater. Res. 19 (2004) 3-20, https://doi.org/10.1557/jmr.2004.19.1.3.

[46] K. Mukunthan, E.B. Hawbolt, Modeling recovery and recrystallization kinetics in cold-rolled Ti-Nb stabilized interstitial-free steel, Metall. Mater. Trans. A 27 (1996) 3410-3423, https://doi.org/10.1007/BF02595434.

[47] G.A. Salishchev, M.A. Tikhonovsky, D.G. Shaysultanov, N.D. Stepanov, A.V. Kuznetsov, I.V. Kolodiy, A.S. Tortika, O.N. Senkov, Effect of Mn and v on structure and mechanical properties of high-entropy alloys based on $\mathrm{CoCrFeNi}$ system, J. Alloy. Comp. 591 (2014) 11-21, https://doi.org/10.1016/j.jallcom. 2013.12.210.

[48] S. Sheikh, S. Shafeie, Q. Hu, J. Ahlström, C. Persson, J. Veselý, J. Zýka, U. Klement, S. Guo, Alloy design for intrinsically ductile refractory high-entropy alloys, J. Appl. Phys. 120 (2016) 164902, https://doi.org/10.1063/1.4966659.

[49] J.Q. Yao, X.W. Liu, N. Gao, Q.H. Jiang, N. Li, G. Liu, W.B. Zhang, Z.T. Fan, Phase stability of a ductile single-phase BCC Hf $0.5 \mathrm{Nb} 0.5 \mathrm{Ta} 0.5 \mathrm{Ti} 1.5 \mathrm{Zr}$ refractory highentropy alloy, Intermetallics 98 (2018) 79-88, https://doi.org/10.1016/j.intermet. 2018.04.023.

[50] Y.D.D. Wu, Y.H.H. Cai, T. Wang, J.J.J. Si, J. Zhu, Y.D.D. Wang, X.D.D. Hui, A refractory Hf25Nb25Ti25Zr25 high-entropy alloy with excellent structural stability and tensile properties, Mater. Lett. 130 (2014) 277-280 accessed https://www. 
sciencedirect.com/science/article/pii/S0167577X1400946X, Accessed date: 5 September 2018.

[51] C.M. Lin, C.C. Juan, C.H. Chang, C.W. Tsai, J.W. Yeh, Effect of Al addition on mechanical properties and microstructure of refractory AlxHfNbTaTiZr alloys, J. Alloy. Comp. (2015), https://doi.org/10.1016/j.jallcom.2014.11.064.

[52] C.C. Juan, K.K. Tseng, W.L. Hsu, M.H. Tsai, C.W. Tsai, C.M. Lin, S.K. Chen, S.J. Lin, J.W. Yeh, Solution strengthening of ductile refractory HfMoxNbTaTiZr high-entropy alloys, Mater. Lett. 175 (2016) 284-287, https://doi.org/10.1016/j.matlet. 2016.03.133.

[53] S. Guo, C. Ng, J. Lu, C.T. Liu, Effect of valence electron concentration on stability of fcc or bcc phase in high entropy alloys, J. Appl. Phys. 109 (2011) 103505, https:// doi.org/10.1063/1.3587228.

[54] E. Bertrand, P. Castany, I. Péron, T. Gloriant, Twinning system selection in a metastable $\beta$-titanium alloy by Schmid factor analysis, Scr. Mater. 64 (2011) 1110-1113, https://doi.org/10.1016/J.SCRIPTAMAT.2011.02.033.

[55] Y. Yang, S.Q. Wu, G.P. Li, Y.L. Li, Y.F. Lu, K. Yang, P. Ge, Evolution of deformation mechanisms of Ti-22.4Nb-0.73Ta-2Zr-1.340 alloy during straining, Acta Mater 58 (2010) 2778-2787, https://doi.org/10.1016/J.ACTAMAT.2010.01.015.

[56] S. Sadeghpour, S.M. Abbasi, M. Morakabati, L.P. Karjalainen, D.A. Porter, Effect of cold rolling and subsequent annealing on grain refinement of a beta titanium alloy showing stress-induced martensitic transformation, Mater. Sci. Eng. A 731 (2018) 465-478, https://doi.org/10.1016/j.msea.2018.06.050.

[57] K.N. Wertz, J.D. Miller, O.N. Senkov, Toward multi-principal component alloy discovery: assessment of CALPHAD thermodynamic databases for prediction of novel ternary alloy systems, J. Mater. Res. (2018) 1-14, https://doi.org/10.1557/ jmr.2018.61.

[58] E. Nes, N. Ryum, O. Hunderi, On the Zener drag, Acta Metall. 33 (1985) 11-22, https://doi.org/10.1016/0001-6160(85)90214-7.

[59] K. Huang, K. Marthinsen, Q. Zhao, R.E. Logé, The double-edge effect of secondphase particles on the recrystallization behaviour and associated mechanical properties of metallic materials, Prog. Mater. Sci. 92 (2018) 284-359, https://doi.
org/10.1016/J.PMATSCI.2017.10.004

[60] F.J. Humphreys, M. Hatherly, Recrystallization and Related Annealing Phenomena, Elsevier, 2004.

[61] M.V. Klimova, D.G. Shaysultanov, S.V. Zherebtsov, N.D. Stepanov, Effect of second phase particles on mechanical properties and grain growth in a CoCrFeMnNi high entropy alloy, Mater. Sci. Eng. A 748 (2019) 228-235, https://doi.org/10.1016/J. MSEA.2019.01.112.

[62] Z. Wang, A. Genc, I. Baker, Direct versus indirect particle strengthening in a strong, ductile FeNiMnAlTi high entropy alloy, Mater. Char. 132 (2017) 156-161, https:// doi.org/10.1016/J.MATCHAR.2017.08.019.

[63] T. Saito, T. Furuta, J.-H. Hwang, S. Kuramoto, K. Nishino, N. Suzuki, R. Chen, A. Yamada, K. Ito, Y. Seno, T. Nonaka, H. Ikehata, N. Nagasako, C. Iwamoto, Y. Ikuhara, T. Sakuma, Multifunctional alloys obtained via a dislocation-free plastic deformation mechanism, Science 300 (2003) 464-467, https://doi.org/10.1126/ science.1081957.

[64] C. Varvenne, A. Luque, W.A. Curtin, Theory of strengthening in fcc high entropy alloys, Acta Mater. 118 (2016), https://doi.org/10.1016/j.actamat.2016.07.040.

[65] I. Toda-Caraballo, P.E.J. Rivera-Díaz-del-Castillo, Modelling solid solution hardening in high entropy alloys, Acta Mater. 85 (2015) 14-23, https://doi.org/10. 1016/j.actamat.2014.11.014.

[66] K.C. Chen, S.M. Allen, J.D. Livingston, Factors affecting the room-temperature mechanical properties of TiCr2-base Laves phase alloys, Mater. Sci. Eng. A 242 (1998) 162-173, https://doi.org/10.1016/S0921-5093(97)00526-1.

[67] K.C. Chen, F. Chu, P.G. Kotula, D. Thoma, HfCo2 Laves phase intermetallics-part II: elastic and mechanical properties as a function of composition, Intermetallics 9 (2001) 785-798, https://doi.org/10.1016/S0966-9795(01)00067-X.

[68] N. Takata, H. Ghassemi-Armaki, M. Takeyama, S. Kumar, Nanoindentation study on solid solution softening of Fe-rich Fe2Nb Laves phase by $\mathrm{Ni}$ in $\mathrm{Fe}-\mathrm{Nb}-\mathrm{Ni}$ ternary alloys, Intermetallics 70 (2016) 7-16, https://doi.org/10.1016/J.INTERMET.2015 11.003. 